\title{
Intensified P-xylene Production Process through Toluene and Methanol Alkylation
}

DOI:

10.1021/acs.iecr.8b00681

\section{Document Version}

Accepted author manuscript

Link to publication record in Manchester Research Explorer

\section{Citation for published version (APA):}

Liu, J., Yang, Y., Wei, S., Shen, W., Rakovitis, N., \& Li, J. (2018). Intensified P-xylene Production Process through Toluene and Methanol Alkylation. Industrial \& Engineering Chemistry Research.

https://doi.org/10.1021/acs.iecr.8b00681

\section{Published in:}

Industrial \& Engineering Chemistry Research

\section{Citing this paper}

Please note that where the full-text provided on Manchester Research Explorer is the Author Accepted Manuscript or Proof version this may differ from the final Published version. If citing, it is advised that you check and use the publisher's definitive version.

\section{General rights}

Copyright and moral rights for the publications made accessible in the Research Explorer are retained by the authors and/or other copyright owners and it is a condition of accessing publications that users recognise and abide by the legal requirements associated with these rights.

\section{Takedown policy}

If you believe that this document breaches copyright please refer to the University of Manchester's Takedown Procedures [http://man.ac.uk/04Y6Bo] or contact uml.scholarlycommunications@manchester.ac.uk providing relevant details, so we can investigate your claim.

\section{OPEN ACCESS}




\section{Intensified P-xylene Production Process through Toluene and Methanol Alkylation}

Jing Liu, Yu Yang, Shun'an Wei, Weifeng Shen, Nikolaos Rakovitis, and Jie Li

Ind. Eng. Chem. Res., Just Accepted Manuscript • DOI: 10.1021/acs.iecr.8b00681 • Publication Date (Web): 29 Aug 2018

Downloaded from http://pubs.acs.org on September 4, 2018

\section{Just Accepted}

"Just Accepted" manuscripts have been peer-reviewed and accepted for publication. They are posted online prior to technical editing, formatting for publication and author proofing. The American Chemical Society provides "Just Accepted" as a service to the research community to expedite the dissemination of scientific material as soon as possible after acceptance. "Just Accepted" manuscripts appear in full in PDF format accompanied by an HTML abstract. "Just Accepted" manuscripts have been fully peer reviewed, but should not be considered the official version of record. They are citable by the Digital Object Identifier (DOI®). "Just Accepted" is an optional service offered to authors. Therefore, the "Just Accepted" Web site may not include all articles that will be published in the journal. After a manuscript is technically edited and formatted, it will be removed from the "Just Accepted" Web site and published as an ASAP article. Note that technical editing may introduce minor changes to the manuscript text and/or graphics which could affect content, and all legal disclaimers and ethical guidelines that apply to the journal pertain. ACS cannot be held responsible for errors or consequences arising from the use of information contained in these "Just Accepted" manuscripts. 


\title{
Intensified $\boldsymbol{P}$-xylene Production Process through Toluene and Methanol Alkylation
}

\author{
Jing Liu ${ }^{1}$, Yu Yang ${ }^{1}$, Shun'an Wei ${ }^{1}$, Weifeng Shen ${ }^{1, *}$, Nikolaos Rakovitis ${ }^{2}, \mathrm{Jie} \mathrm{Li}^{2}$,* \\ ${ }^{1}$ School of Chemistry and Chemical Engineering, Chongqing University, Chongqing 400044, China \\ ${ }^{2}$ Centre for Process Integration, School of Chemical Engineering and Analytical Science, The University of \\ Manchester, Manchester M139PL, UK \\ * Corresponding author: shenweifeng@cqu.edu.cn(W.S.), or jie.li-2@ manchester.ac.uk(J.L.)
}

\begin{abstract}
The production of $p$-xylene has received more and more attention since it is widely used in chemical synthetic resins, pharmaceutical, chemical fiber, and pesticides industries. The $p$-xylene production through toluene alkylation is considered to be more promising due to high selectivity of $p$-xylene and little environmental impact compared to other methods. Although the existing $p$-xylene production process through toluene alkylation could achieve high selectivity of $p$-xylene, the methanol conversion is still as low as $70.0 \%$, requiring methanol recovery and recycle system and resulting in additional loss of toluene in the downstream separation of light component, methanol and toluene. Based on these findings, an intensified $p$-xylene production process through toluene alkylation with complete methanol conversion is proposed and simulated using Aspen Plus V8.4 ${ }^{\circledR}$. The optimal operating conditions for the alkylation reactor are obtained using the sensitivity analysis tool and sequential quadratic programming (SQP) optimization solver in Aspen Plus V8.4 ${ }^{\circledR}$. It is found that the methanol conversion could reach $98.0 \%$ with $p$-xylene selectivity of $92.0 \%$ through increasing reaction temperature to $442.5{ }^{\circ} \mathrm{C}$ and pressure to 4.0 bar compared to the existing process, resulting in the removal of methanol recovery and recycle system and less toluene loss in the downstream separation. The comparative evaluations demonstrate that the
\end{abstract}


proposed process is more efficient than the existing process based on economic and environmental metrics. The overall TAC is reduced by $4.71 \%$ and $\mathrm{CO}_{2}$ emissions are decreased by $40.2 \%$ compared to the existing process without heat integration.

Keywords: Process design, $p$-xylene, toluene alkylation, heat integration, TAC, carbon emission

\section{Introduction}

The production of $p$-xylene has received more and more attention from both academia and chemical industries since it is one of the most important petrochemical intermediates that is widely used in chemical synthetic resins, pharmaceutical, chemical fiber, and pesticides industries. ${ }^{1-4}$ The demand of $p$-xylene in the world has been greatly increasing in recent years, especially from China. ${ }^{5} \quad P$-xylene is mainly produced by selective toluene disproportionation $^{6-8}, \mathrm{C}_{8}$ aromatic isomerization ${ }^{9}$, and adsorptive separation or crystallization from other xylene isomers ${ }^{10-11}$. Although these methods produce high-purity $p$-xylene, relatively high cost is required because of either expensive raw materials in selective toluene disproportionation or low selectivity of $p$-xylene in $\mathrm{C}_{8}$ aromatic isomerization. The production of $p$-xylene through adsorptive separation or crystallization requires more energy, due to very close boiling points of xylene isomers and low selectivity of $p$-xylene. ${ }^{11}$ Meanwhile, these production processes are associated with the generation of a considerable amount of by-products (e.g., ethylbenzene) resulting in environmental pollution.

With the significant reduction of toluene price arising from great increase of its global productivity $^{12}$, the selective alkylation using toluene as a feedstock for synthesis of $p$-xylene has been identified as a promising alternative. ${ }^{13-17}$ The toluene is reacted with another 
feedstock methanol to produce $p$-xylene directly. Side reactions could also take place simultaneously to generate $m$-xylene and $o$-xylene. Unreacted toluene and methanol are recovered in the downstream distillation processes and recycled to the feed. $P$-xylene is separated from byproducts $m$-xylene and $o$-xylene in the downstream reactive distillation. Compared to other existing methods, this method requires mild reaction conditions (i.e., 400.0 500.0 ${ }^{\circ} \mathrm{C}$ and 3.0 4.0 bar) and could result in high utilization of toluene with excessive methanol and high selectivity of $p$-xylene. ${ }^{13-17}$ However, this production process is viable only when the cost of methanol is low (e.g., $<\$ 0.35 /$ ton) and the selectivity of $p$-xylene is high enough (e.g., > $90.0 \%) .{ }^{18,35}$

To reach high selectivity of $p$-xylene in toluene methylation, Breen et al. ${ }^{18,19}$ and Sotelo et al. ${ }^{20}$ found out the selectivity of Mg-modified ZSM-5 catalyst to $p$-xylene can achieve as high as nearly $100 \%$. Zhao ${ }^{21}$ demonstrated that high selectivity of $p$-xylene on ZSM-5 zeolite catalyst could be always obtained. High selectivity of $p$-xylene not only inhibits the production of other unwanted isomers of xylene, but also increases $p$-xylene productivity and improves process economics. Meanwhile, it has been experimentally demonstrated that methanol conversion could remain at $100 \%$ over Mg-modified ZSM-5 catalyst even with highest magnesium content. ${ }^{22-24}$ Ashraf et al. ${ }^{15}$ designed a $p$-xylene production process through toluene methylation with Mg-modified ZSM-5 catalyst. Their objective is to achieve maximum selectivity of $p$-xylene and to obtain 99.7 wt $\%$ of $p$-xylene. However, the production process of $p$-xylene still requires the present situation of methanol and toluene two-component separation cycle due to incomplete reaction in the existing reactor. In addition, the separation of light component, methanol and toluene in the downstream distillation could 
lead to additional loss of toluene.

In order to overcome the disadvantages of Ashraf et al. ${ }^{15}$ and improve process economics, an intensified $p$-xylene production process through toluene and methanol alkylation is proposed in this study where the methanol recovery and recycle system are cut off. A systematic design procedure for the proposed process involving thermodynamic and kinetic insights, process simulation, sensitivity analysis, and optimization through Sequential Quadratic Programming tool implemented in Aspen Plus V8.4 ${ }^{\circledR}$ is proposed to identify the optimal operating conditions and reduce toluene loss in the downstream separation. Then, heat integration is conducted using pinch analysis tool implemented in Aspen Plus V8.4 ${ }^{\circledR}$ to improve energy efficiency and further reduce total cost. Finally, two examples are used to illustrate the advantages of the proposed process based on economic and environmental metrics.

\section{Proposed $p$-xylene production process}

Figure 1 illustrates the proposed $p$-xylene production process through toluene methylation. The fresh feeds (i.e. toluene and methanol) are first preheated and then vaporized in the heating furnace before entering the alkylation reactor. In the alkylation reactor, toluene is primarily reacted with methanol to produce $p$-xylene. Other side reactions also take place such as methanol self-decomposition into hydrocarbons and water, and $p$-xylene conversion to $m$-xylene and $o$-xylene. A condenser is added to partially cooling outlet stream of the reactor to get light compounds such as gaseous hydrocarbon $(\mathrm{GH})$ which are separated out in the subsequent flash column. The cooled GH is separated out at the top of flash column and the bottom liquid is fed into a decanting vessel for further separation where the upper layer product is water and the lower layer is aromatic mixture including benzene, toluene, $p$-xylene, 
$m$-xylene, and $o$-xylene. The aromatic mixture is separated further into benzene, toluene, $p$-xylene, and mixed aromatics through two distillation columns and one reactive distillation unit. 99.7 wt $\%$ of $p$-xylene is obtained at the top of the reactive column. Compared to the existing process ${ }^{15}$ which is depicted in Figure 2, the proposed process does not require methanol recovery and recycle system due to almost complete conversion of methanol. Therefore, a trace amount of methanol in the reactor effluent could be found in the proposed process, whilst non-negligible amount of unconverted methanol existed in the reactor effluent in the existing process reported in the literature. ${ }^{15}$

\section{PLEASE INSERT FIGURE 1 HERE}

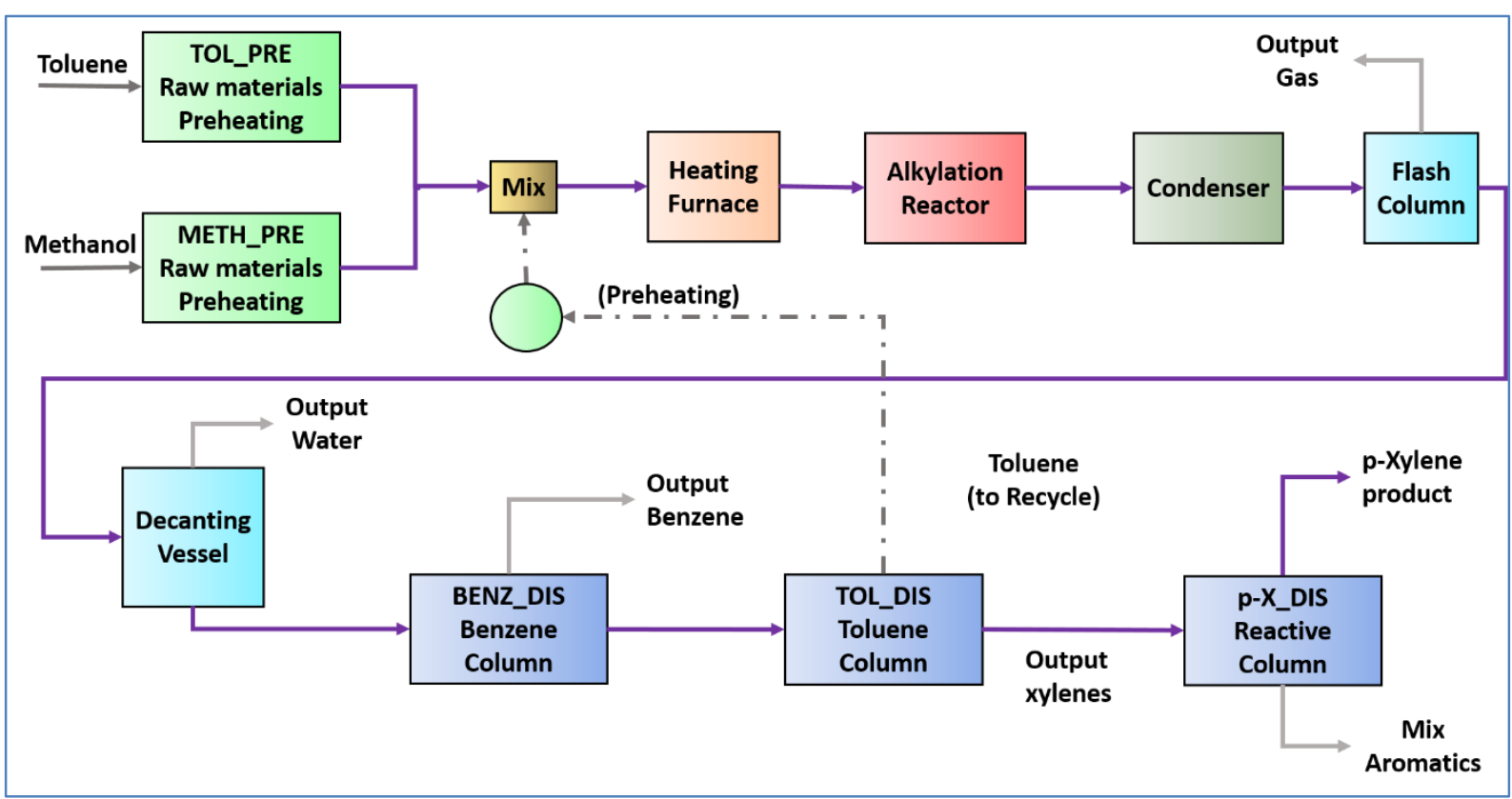

Figure 1 The proposed $p$-xylene production process through toluene methylation with complete conversion of methanol

PLEASE INSERT FIGURE 2 HERE 


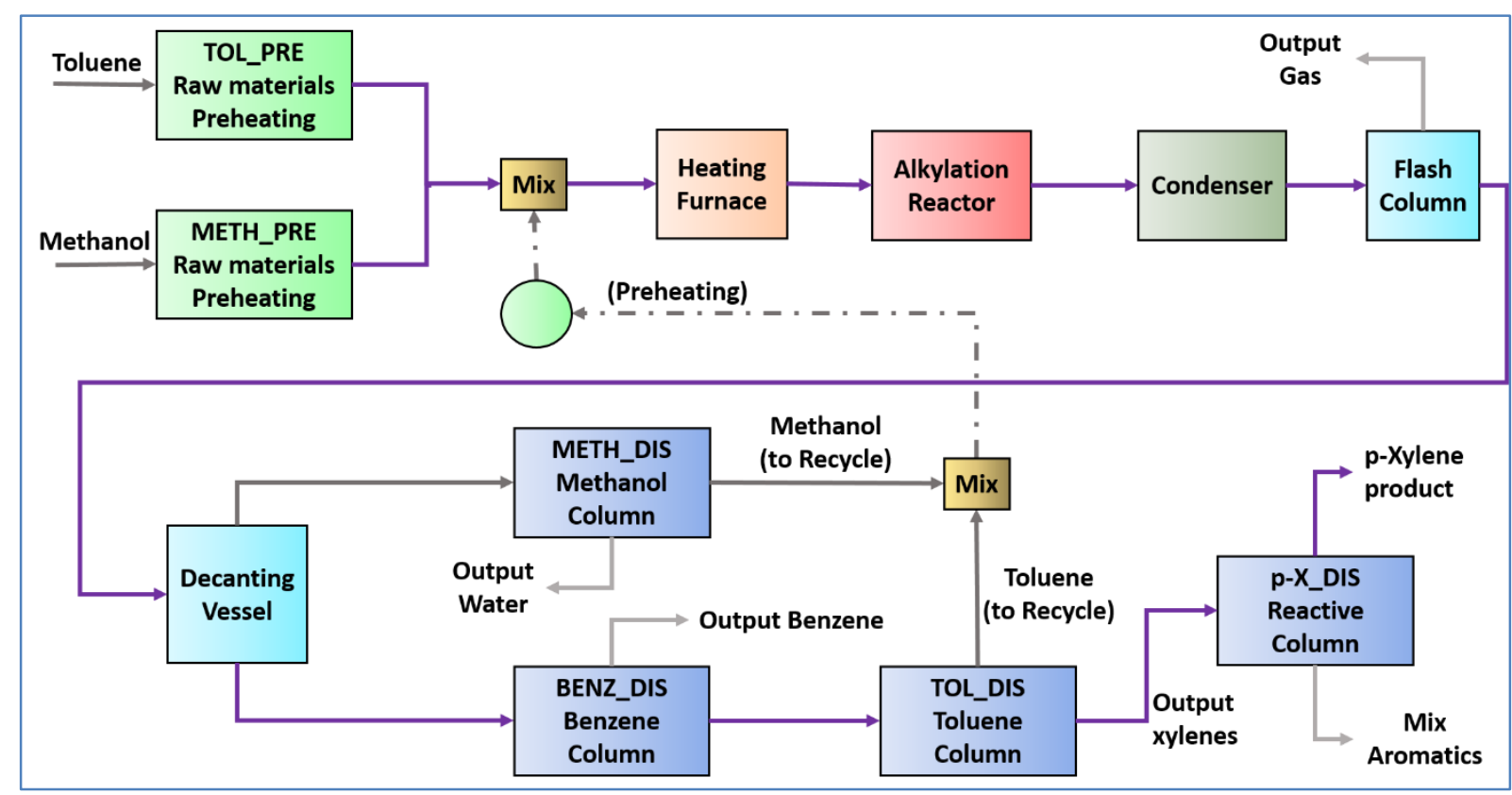

Figure 2 The existing $p$-xylene production process by toluene methylation ${ }^{15}$

\subsection{Reaction kinetics in alkylation reaction}

In the alkylation reactor, toluene is primarily reacted with methanol to produce $p$-xylene. It has been shown that methanol is completely converted in the temperature range of $400-$ 600 oC. ${ }^{24-25}$ Mantha et al. $^{26}$ and Bhat et al. ${ }^{27}$ developed a kinetic model based on the Langmuir-Hinshelwood approach, ignoring other products than xylene generated from the side reactions of methanol. Vayssilov et al. ${ }^{28}$ proposed a power law kinetic model only considering the reactions of toluene alkylation and xylene isomerization. However, the experimental data that were used for kinetic model development is generated at a unique temperature of $227{ }^{\circ} \mathrm{C}$. Sotelo et al. ${ }^{20}$ developed a kinetic model over the Mg-modified catalysts in a fixed-bed reactor with the consideration of diffusional effects and the influence of $p$-xylene isomerization over the external zeolite surface, reproducing the experimental product distribution with an average relative error of $6.8 \%$. Valverde et al. ${ }^{25}$ developed a simple power law kinetic model for toluene alkylation with methanol over Mg-modified 
ZSM-5 catalyst considering all possible side reactions of methanol. The catalyst used contains $1.09 \mathrm{wt} \% \mathrm{Mg}$ and $35 \mathrm{wt} \%$ sodium montmorillonite as a binder with an average particle size of $0.75 \mathrm{~mm}$. The reaction kinetic model ${ }^{25}$ is introduced as follows,

$$
\begin{array}{ll}
\text { Toluene }+ \text { Methanol } \rightarrow \mathrm{p}-\text { Xylene }+ \text { Water } & \mathrm{r}_{1}=k_{1} p_{\mathrm{T}} p_{\mathrm{M}} \\
\text { 2Methanol } \rightarrow \mathrm{GH}+2 \text { Water } & \mathrm{r}_{2}=k_{2} p_{\mathrm{M}}^{2} \\
\text { Toluene } \rightarrow \frac{1}{2} \text { Benzene }+\frac{1}{2} \mathrm{p}-\text { Xylene } & \mathrm{r}_{3}=k_{3} p_{\mathrm{T}} \\
\mathrm{p}-\text { Xylene } \rightarrow \text { Toluene }+\frac{1}{2} \mathrm{GH} & \mathrm{r}_{4}=k_{4} p_{\mathrm{p}-\mathrm{X}} \\
\mathrm{p}-\text { Xylene } \rightarrow \frac{1}{2}(\mathrm{~m}-\text { Xylene }+\mathrm{o}-\text { Xylene }) & \mathrm{r}_{5}=k_{5} p_{\mathrm{p}-\mathrm{X}}
\end{array}
$$

where, $k_{i}$ denotes rate constant and $p$ represents partial pressure. Gaseous hydrocarbons $(\mathrm{GH})$ indicate light species (e.g., methane, ethane, ethylene, propane, and butanes), which is represented as pure ethylene to ensure stoichiometric balance in eq. 2 . The kinetic parameters are given in Table 1.

\section{PLEASE INSERT TABLE 1 HERE}

Table 1 Kinetic parameters of toluene methylation over Mg-modified ZSM-5 zeolite catalyst ${ }^{25}$

\begin{tabular}{lll}
\hline reaction & $\begin{array}{l}\text { pre-exponential factor, } \\
\mathrm{A}_{\mathrm{i}}, \mathrm{mol} /\left(\mathrm{g} \cdot \mathrm{h} \cdot \mathrm{atm}^{2}\right) \\
\text { or } \mathrm{mol} /(\mathrm{g} \cdot \mathrm{h} \cdot \mathrm{atm})\end{array}$ & $\begin{array}{l}\text { activation energy, } \\
\mathrm{E}_{\mathrm{i}},(\mathrm{kJ} / \mathrm{mol})\end{array}$ \\
\hline 1 & $403 \pm 5$ & $45.7 \pm 0.4$ \\
2 & $1346 \pm 64$ & $50.6 \pm 0.5$ \\
3 & $96.2 \pm 1$ & $59.0 \pm 0.5$ \\
4 & $0.3815 \pm 0.05$ & $19.6 \pm 0.7$ \\
5 & $46.94 \pm 0.5$ & $48.9 \pm 0.3$ \\
\hline
\end{tabular}

The kinetic rate constant $k_{i}$ is related to $A_{i}$ and $E_{i}$ as Eq. 6 .

$$
k_{i}=A_{i} T^{n} e^{\frac{-E_{i}}{R T}}
$$

It is shown that the reactions given in eqs. 1, 3, and 4 occur preferentially inside pores of the catalyst. Consequently, the effectiveness factors $\eta_{1}, \eta_{3}$, and $\eta_{4}$ are used to account for 
diffusion limitations. ${ }^{25}$ The values of the effectiveness factors, $\eta_{3}$ and $\eta_{4}$ are given in Table 2 for three different temperatures: $460.0{ }^{\circ} \mathrm{C}, 500.0{ }^{\circ} \mathrm{C}$, and $540.0{ }^{\circ} \mathrm{C}$. The value of effectiveness factor $\eta_{1}$ is 0.98 which is approximated to be 1 .

\section{PLEASE INSERT TABLE 2 HERE}

Table 2 Effectiveness factors for toluene methylation over Mg modified ZSM- 5 catalyst $^{25}$

\begin{tabular}{lll}
\hline temperature, ${ }^{\circ} \mathrm{C}$ & $\eta_{3}$ & $\eta_{4}$ \\
\hline 460.0 & $0.7781 \pm 0.117$ & $2.977 \pm 1.10$ \\
500.0 & $0.5335 \pm 0.170$ & $3.212 \pm 0.59$ \\
540.0 & $0.4470 \pm 0.320$ & $3.201 \pm 0.97$ \\
\hline
\end{tabular}

The aforementioned reaction kinetic model with the given parameter values ${ }^{25}$ are quantitatively validated by Ashraf et al. ${ }^{15}$ The simulation results are in agreement with the experimental results from Sotelo et al. ${ }^{20}$ The same reaction kinetic model was also used to investigate the effects of temperature, pressure, space time and toluene-to-methanol feed ratio on toluene conversion, xylene selectivity and p-xylene selectivity using the sensitivity analysis feature in Aspen Plus and obtain the best reaction conditions including temperature and pressure. ${ }^{29}$ It should be noted that although the kinetic parameters and effectiveness factors were reported in three temperatures $460{ }^{\circ} \mathrm{C}, 500{ }^{\circ} \mathrm{C}$ and $540{ }^{\circ} \mathrm{C}$, they are valid for the temperatures ranging from $400{ }^{\circ} \mathrm{C}$ to $540{ }^{\circ} \mathrm{C}$ and for the pressures ranging from 1 to 15 bar as indicated in the sensitivity analysis of Ashraf et al. ${ }^{15}$ Hence, the same kinetic model with the given parameter values are also used in this work. The mean values for each of parameters given in Tables 1 are input directly. However, for the data in Table 2, the specific effectiveness factors corresponding to other temperatures are not given and then these factors are calculated based on the Eqs. S1-S4 and the iterative algorithm block diagram of calculating effectiveness diffusion coefficient De as illustrated in Figure S1 of Supporting 
Information.

\subsection{Reaction kinetics in reactive distillation}

It is well known that $p$-xylene and $m$-xylene are difficult to separate using conventional distillation since they have very close boiling point at 1.0 bar as shown in Table 3 . However, $m$-xylene can be selectively tert-butylated (reaction with di-tert-butyl-benzene) in the presence of aluminum chloride under mild alkylation conditions to form tert-bytyl $m$-xylene (TBMX) with higher boiling point as shown in Table 3, which can be separated from $p$-xylene. When modeling the reactive distillation column in Aspen Plus, the reactions can be considered to reach equilibrium as reported in the work of in Venkataraman ${ }^{30}$, based on the experimental work of Saito et al. ${ }^{31}$ The reaction equations are presented in eqs. 7-8. The corresponding equilibrium constants are given in eqs. 9-10, respectively.

$$
\begin{aligned}
& \mathrm{DTBB}+\mathrm{m}-\mathrm{X} \rightarrow \mathrm{TBMX}+\mathrm{TBB} \\
& \mathrm{TBB}+\mathrm{m}-\mathrm{X} \rightarrow \mathrm{TBMX}+\mathrm{B} \\
& K_{1}^{R}=\frac{x_{T B M X} x_{T B B}}{x_{D T B B} x_{m-X}}=0.6 \\
& K_{2}^{R}=\frac{x_{T B M X} x_{B}}{x_{T B B} x_{m-X}}=0.16
\end{aligned}
$$

In the equations above, DTBB represents di-tert-butyl-benzene, TBB refers to tert-butyl-benzene, TBMX is tert-butyl $m$-xylene, and benzene is abbreviated to $\mathrm{B}$. Equilibrium data are given by Saito et al. ${ }^{31}$

\section{PLEASE INSERT TABLE 3 HERE}

Table 3 Boiling and freezing points of some of the materials present in the process

\begin{tabular}{llll}
\hline material & normal boiling point, ${ }^{\circ} \mathrm{C}$ & freezing point, ${ }^{\circ} \mathrm{C}$ & reference \\
\hline $\mathrm{p}-\mathrm{X}$ & 138.3 & 13.3 & 32 \\
$\mathrm{~m}-\mathrm{X}$ & 139.1 & -47.8 & 32 \\
$\mathrm{o}-\mathrm{X}$ & 144.4 & -25.2 & 32 \\
$\mathrm{TBMX}$ & 205.5 & -17.0 & 32 \\
\hline
\end{tabular}




\section{Process design}

The proposed process is used to produce $179.0 \mathrm{kmol} / \mathrm{h} p$-xylene product with a purity of $99.7 \mathrm{wt} \%$ using $393.0 \mathrm{kmol} / \mathrm{h}$ fresh methanol and $215.0 \mathrm{kmol} / \mathrm{h}$ fresh toluene as feeds. Figure 3 presents the design procedure for the proposed $p$-xylene production process. First, process simulation of the existing process ${ }^{15}$ is conducted in Aspen Plus to construct a base case. Then, optimal operating conditions in the alkylation reactor are generated through sensitivity analysis and Sequential Quadratic Programming (SQP) optimization method built in Aspen Plus. The objective is to achieve complete methanol conversion subject to some constraints such as $p$-xylene selectivity constraints. After that, heat integration is conducted to improve energy efficiency of the proposed process. Finally, the proposed process is evaluated based on the total annualized cost and carbon emissions.

PLEASE INSERT FIGURE 3 HERE

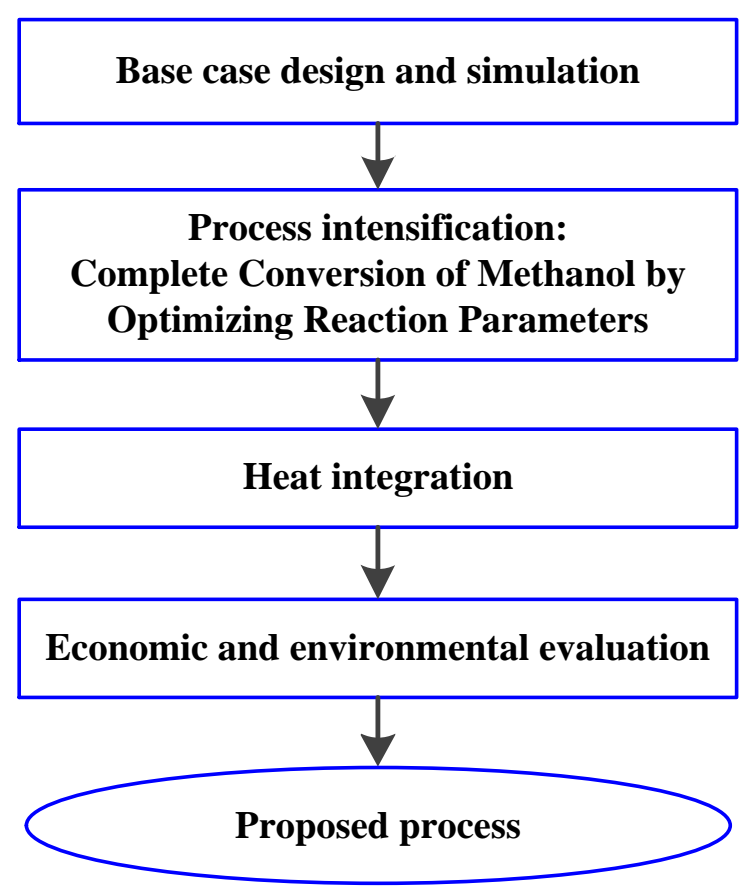

Figure 3 A systematic design procedure for the proposed $p$-xylene production process 


\subsection{Optimal operating conditions for the reactor}

Some researchers have performed simulation of an isothermal packed bed alkylation reactor using the kinetic model of Valverde. ${ }^{15,25}$ To ensure fair comparison, the same reactor design $^{15}$ is used here including the reactor type and size to ensure a fair comparison and demonstrate that the improvement is not contributed from changing the reactor size. The required key operating conditions for the reactor include toluene-to-methanol feed ratio $\mathrm{m}$, temperature $T$, and pressure $P$. The objective is to maximize methanol conversion denoted as $z$, which is represented below:

$$
\mathrm{z}=\left(\frac{\text { inlet methanol-outlet methanol }}{\text { inlet methanol }}\right) \times 100
$$

Subject to a set of constraints as follows:

The outlet flow rate of $p$-xylene from the reactor should exceed the minimum value of $187.0 \mathrm{kmol} / \mathrm{h}$ reported by Ashraf et al. ${ }^{15}$ :

$$
F_{p-X} \geq F_{p-X}^{\min }
$$

The concentration of methanol in the alkylation reactor effluent should be less than a maximum concentration, which is assumed to be $0.3 \mathrm{wt} \%$ :

$$
M \% \leq M \%^{\max }
$$

The $p$-xylene selectivity (denoted as $S_{p-X}$ ) should also exceed a minimum value of selectivity, which is assumed to be $90.0 \%$ :

$$
S_{p-X}=\left(\frac{F_{p-X}}{F_{p-X}+F_{m-X}+F_{o-X}}\right) \times 100 \geq S_{p-X}^{\min }
$$

The toluene conversion should exceed a minimum value, which is about $23.0 \%$ :

$$
X_{\text {toluene }}=\left(\frac{\text { inlet toluene-outlet toluene }}{\text { inlet toluene }}\right) \times 100 \geq X_{\text {toluene }}^{\text {min }}
$$


Besides eqs. 12-15, there are also other constraints such as mass and energy balances, which is implicitly implemented in Aspen Plus.

In addition, the toluene-to-methanol feed ratio $m$, temperature $T$, and pressure $P$ must meet their lower and upper bounds, as described by the following equations:

$$
\begin{aligned}
& m^{L} \leq m \leq m^{U} \\
& T^{L} \leq T \leq T^{U} \\
& P^{L} \leq P \leq P^{U}
\end{aligned}
$$

The lower and upper bounds of the toluene-to-methanol feed ratio, temperature, and pressure can be determined based on sensitivity analysis tool implemented in Aspen Plus. The objective function and the constrains are expressed in Fortran statement in Aspen plus and solved using SQP optimization solver implemented in Aspen Plus.

\subsection{Economic evaluation}

The total annual cost (TAC), which consists of total operating cost (TOC) and total capital investment (TCI), is used to evaluate the economics of both the proposed process and the existing process. ${ }^{15}$ The TAC is defined in eq. $19 .{ }^{33}$ Following the suggestion of Turton et al. ${ }^{34}$, the shorter the payback period, the more profitable the project. Thus, a three-year payback period is taken in calculating TAC and the total annual operating time is assumed to be $7920 \mathrm{~h} /$ year.

$$
\mathrm{TAC}=\frac{\mathrm{TCI}}{\text { payback period }}+\mathrm{TOC}
$$

where, the TCI mainly involves equipment purchase cost (pump, heat, reactor, flash, decanter, and distillation columns) and the installation cost of the equipment, and the TOC mainly consists of utility cost (e.g., cost of steam, cooling water, and electricity used in heat exchangers, 
pumps and furnace) and raw materials cost. The economic data for raw materials and utilities are given in Table 4. The inlet and outlet temperatures of cooling water are assumed to be $20{ }^{\circ} \mathrm{C}$ and $25^{\circ} \mathrm{C}$. Pipe and valves costs are neglected because they are much lower than utility and raw material cost. Note that TCI is directly calculated using Aspen Process Economic Analyzer V8.4 ${ }^{\circledR}$ by importing flowsheet simulation results in Aspen Plus simulator. The calculation of TOC is much more complicated. To simplify the calculation, two assumptions are made. First, the fixed operating cost is not taken into account in the calculation of the TOC. Second, the cost of the additional DTBB and TBB that are used in the RD is not considered because their amount and cost is very small in terms of equipment and energy cost. It should be also noted that these two assumptions have no effect on the final comparative results due to the same amount of $p$-xylene produced in both the proposed process and the existing process.

\section{PLEASE INSERT TABLE 4 HERE}

Table 4 Economic data for raw materials and utilities

\begin{tabular}{lccc}
\hline component & price & unit & reference \\
\hline raw materials & & & \\
$\quad$ toluene & 770.0 & $\$ / \mathrm{t}$ & 35 \\
$\quad$ methanol & 380.0 & $\$ / \mathrm{t}$ & 35 \\
utilities & & & \\
$\quad$ fuel & 9.83 & $\$ / \mathrm{GJ}$ & 36 \\
LP steam $\left(6 \mathrm{bar}, 160{ }^{\circ} \mathrm{C}\right)$ & 7.78 & $\$ / \mathrm{GJ}$ & 36 \\
MP steam $\left(11 \mathrm{bar}, 184{ }^{\circ} \mathrm{C}\right)$ & 8.22 & $\$ / \mathrm{GJ}$ & 36 \\
HP steam $\left(42 \mathrm{bar}, 254^{\circ} \mathrm{C}\right)$ & 9.83 & $\$ / \mathrm{GJ}$ & 36 \\
cooling water & 0.10 & $\$ / \mathrm{GJ}$ & 45 \\
electricity & 0.09 & $\$ / \mathrm{kWh}$ & 45 \\
\hline
\end{tabular}

\section{Results and Discussions}

\subsection{Base case}

As mentioned earlier, the existing $p$-xylene production process proposed by Ashraf et al. ${ }^{15}$ is used as our base case. The process flowsheet is illustrated in Figure 4. The detailed stream information is presented in Table S1 of Supporting Information. Table 5 provides a 
summary of the economic evaluation results from Aspen Process Economic Analyzer V8.4 ${ }^{\circledR}$ where $\mathrm{CI}$ is capital investment and $\mathrm{OC}$ is the associated operating cost. The $\mathrm{CI}$ is obtained by the summation of equipment cost and labor cost associated with the project preparation (e.g., installation bulks) while equipment cost is bare equipment cost associated with material. Moreover, the equipment cost is the main cost in the project preparation.

It can be concluded that the utility cost for raw materials heating accounts for $35.2 \%$ of TOC, whilst it accounts for $64.7 \%$ of TOC for the distillation separation system. Note that the overall reaction is exothermic. Thus, cooling water is used to maintain constant reaction temperature at $400{ }^{\circ} \mathrm{C}$. Note that the cooling water cost for the reactor is negligible compared to the utility cost for raw material heating and distillation separation system.

\section{PLEASE INSERT FIGURE 4 HERE}

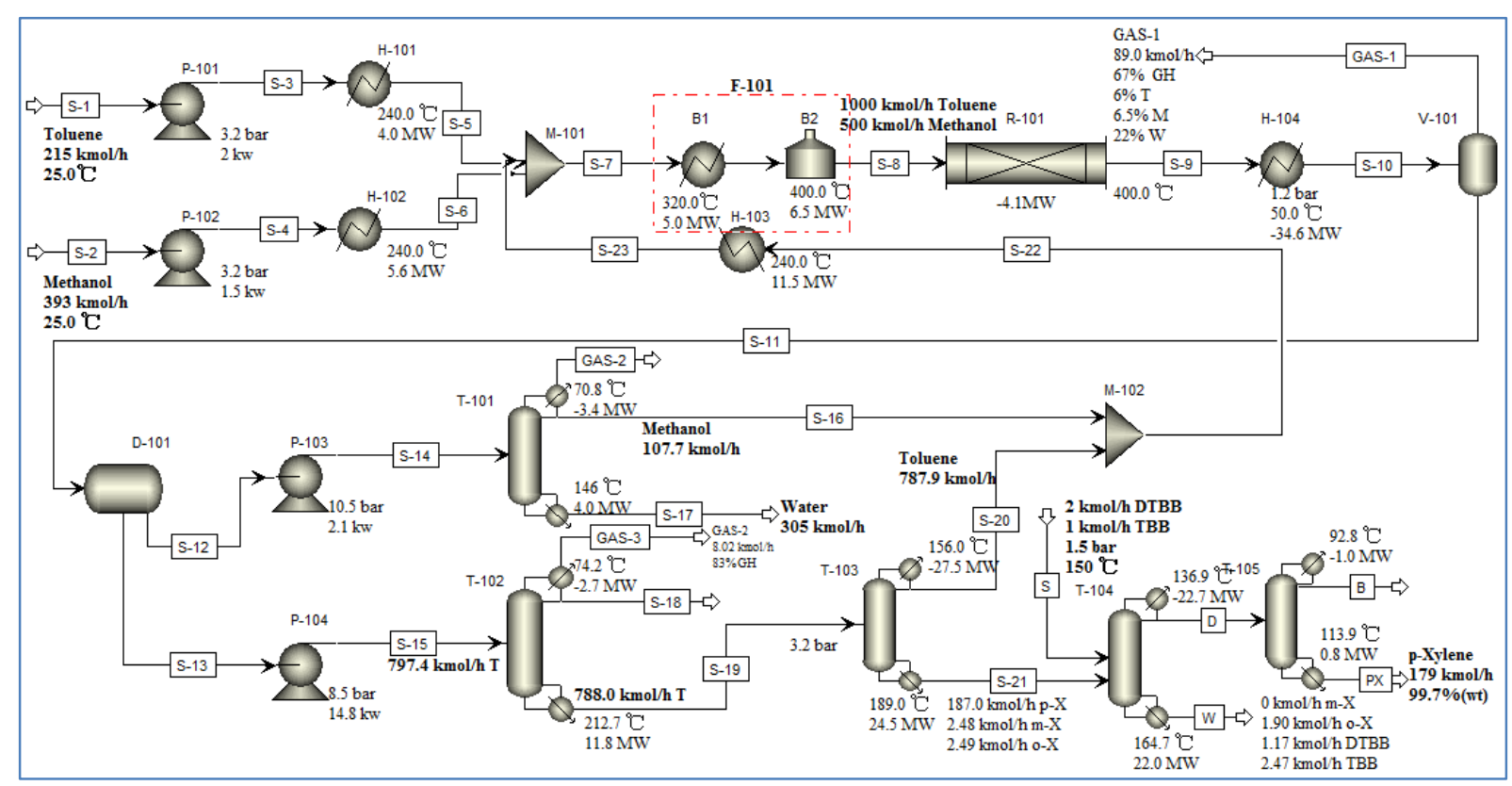

Figure 4 Process flow diagram for the base case

PLEASE INSERT TABLE 5 HERE 
Table 5 Economic evaluation results for the base case

\begin{tabular}{lllll}
\hline equipment & comments & value & CI $(\mathrm{k} \$)$ & OC(k\$/year) \\
\hline P-101 (kw) & toluene pump & 2.0 & 43.9 & 1.5 \\
P-102 (kw) & methanol pump & 1.5 & 42.0 & 1.0 \\
P-103 (kw) & feed pump & 2.1 & 60.9 & 3.2 \\
P-104 (kw) & feed pump & 14.8 & 76.3 & 25.1 \\
H-101 (MW) & heater & 4.0 & 133.9 & 1123.8 \\
H-102 (MW) & heater & 5.6 & 155.3 & 1569.6 \\
H-103 (MW) & heater & 11.5 & 271.7 & 3236.4 \\
H-104 (MW) & condenser & 34.6 & 392.3 & 98.6 \\
F-101 (MW) & fired furnace & 10.3 & 1520.7 & 2998.6 \\
R-101 (MW) & alkylation reactor & 4.1 & 373.0 & 11.7 \\
V-101 & flash vessel & - & $214 . .1$ & - \\
D-101 & decanter & - & 213.3 & - \\
T-101 (aC/R, MW) & methanol distillation column & $3.4 / 4.0$ & 792.0 & 948.5 \\
T-102 (C/R, MW) & benzene distillation column & $2.7 / 11.8$ & 2334.3 & 3318.7 \\
T-103 (C/R, MW) & toluene distillation column & $27.5 / 24.5$ & 4024.1 & 6943.9 \\
T-104 (C/R, MW) & reaction distillation column & $22.7 / 22.0$ & 4562.7 & 5233.7 \\
T-105 (C/R, MW) & p-xylene distillation column & $1.0 / 0.8$ & 734.9 & 147.1 \\
total & - & - & 15731.3 & 22661.4 \\
${ }^{\mathrm{a} C}$ represents Condenser and R represents Reboiler & & & \\
\hline
\end{tabular}

It is also observed that there is a significant difference between condenser and reboiler duties in the benzene distillation column (T-102). The main possible reason is that there are a large amount of heavy components but small amount of light components in the feed to T-102. Therefore, much less distillate is obtained than that in the bottom, leading to much fewer duties required on the top and much more duties required in the bottom. In addition, the partial condenser rather than total condenser is used on the top for the separation of small amount of GH gases in the feed, which further reduces duties required in the condenser.

\subsection{Optimal operating conditions for the reactor}

Sensitivity analysis is conducted to investigate the effect of the three important operating parameters including the toluene-to-methanol feed ratio, operating temperature and pressure on methanol conversion, toluene conversion and p-xylene selectivity. Figure 5 illustrates the 
effect of the toluene-to-methanol feed ratio, $m$, on methanol conversion rates, $C_{M}$, toluene conversion rates, $C_{T}$, $p$-xylene selectivity, $S_{P-X}$ and $p$-xylene flowrate, $F_{P-X}$. From Figure 5 , it can be observed that the methanol conversion decreases along with the increase of $m$. The main possible reason is that the increase of $m$ could lead to the decrease of the space time (weight of catalyst per unit feed flowrate of toluene, $\left.W_{c a t} / F_{T},(\mathrm{~g} \mathrm{~h}) / \mathrm{mol}\right)$, which may decrease the reaction degree of methanol. From Figure 5, it can also be seen that when $m$ increases, the $p$-xylene selectivity is increased due to ultralow residence time of $p$-xylene, which is in good agreement with those reported in the literature. ${ }^{18-20}$ In other words, although the conversion of methanol can reach $98.7 \%$ when $m=1$, the $p$-xylene selectivity is a bit low without satisfying its minimum requirement $(187 \mathrm{kmol} / \mathrm{h})$. In summary, it is very difficult to achieve the complete conversion of methanol and keep high $p$-xylene selectivity simultaneously by only adjusting the value of the toluene-to-methanol feed ratio, $m$.

\section{PLEASE INSERT FIGURE 5 HERE}
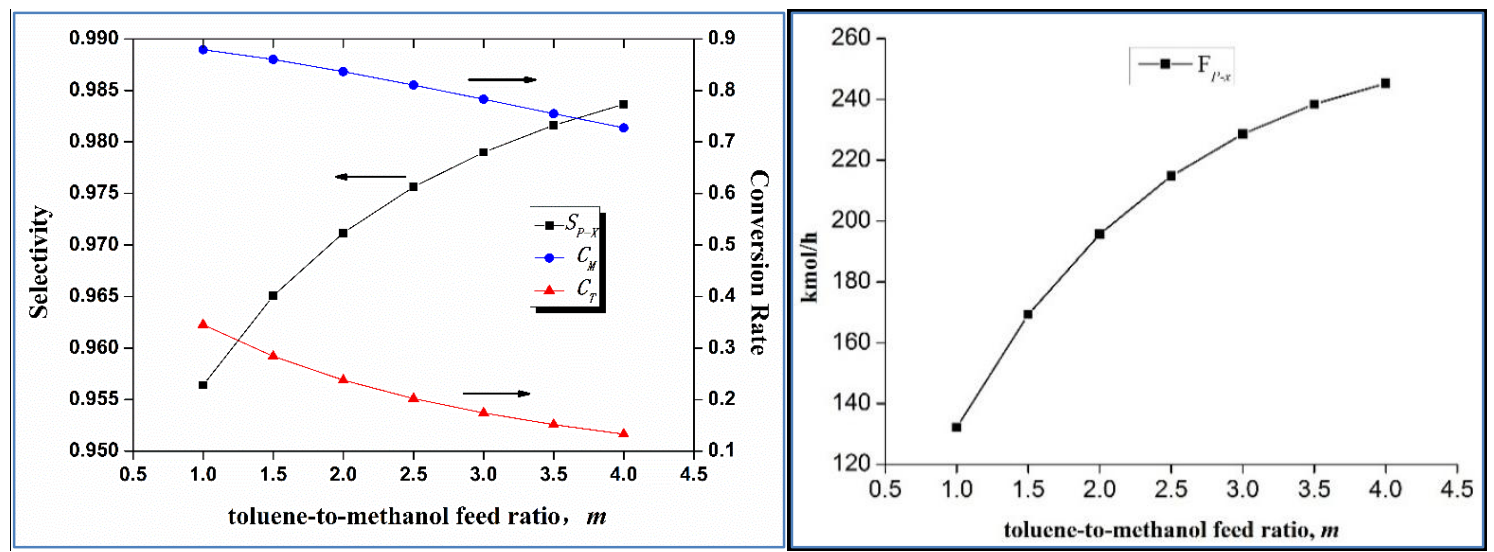

Figure 5 Effect of the toluene-to-methanol feed ratio, $m$, on methanol conversion rates, $C_{M}$, toluene conversion rates, $C_{T}$, $p$-xylene selectivity, $S_{P-X}$, and $p$-xylene flowrate, $F_{P-X}$ where $T_{R}=$ $400.0{ }^{\circ} \mathrm{C}$, and $P_{R}=3.0$ bar

In thermodynamic studies on toluene alkylation with methanol, Wang et al. ${ }^{37}$ found the 
alkylation of benzene, toluene and methanol, carbon deposition of toluene and methanol, and methanol self-transformation can take place spontaneously and irreversibly in forward direction. Methanol could be almost completely converted into low-carbon olefins and water during methanol self-transformation. Dung et al. ${ }^{38}$ and Mehran et al. ${ }^{39}$ concluded that low temperature and high pressure could inhibit the occurrence of side-chain alkylation of toluene, whilst high temperature and low pressure is favorable for inhibiting the occurrence of alkylation of toluene with light olefins. In addition, they found that the maximum toluene conversion and $p$-xylene selectivity was obtained around $427.0{ }^{\circ} \mathrm{C}$.

Experimental results demonstrate that methanol conversion rate could reach around $100 \%$ during the temperature range of $400.0 \sim 600.0{ }^{\circ} \mathrm{C} .{ }^{22-24}$ Meanwhile, as illustrated by Ashraf et al. ${ }^{15}$, the selectivity of both xylene and $p$-xylene is more sensitive to the operating pressure. When the pressure is increased to 4.0 bar, the corresponding $p$-xylene selectivity decreases significantly although its conversion increases. Therefore, there is a trade-off between selectivity and conversion, providing an opportunity to achieve higher conversion with some minimum selectivity through optimization. The temperature and pressure of the reactor at 400.0 500.0 ${ }^{\circ} \mathrm{C}, 3.0 \sim 4.0$ bar, respectively, are chosen as the optimization range.

The influences of the operating temperature and pressure on $p$-xylene selectivity and conversion rates of toluene and methanol are shown in Figures 6 and 7a-b, respectively.

\section{PLEASE INSERT FIGURE 6 HERE}




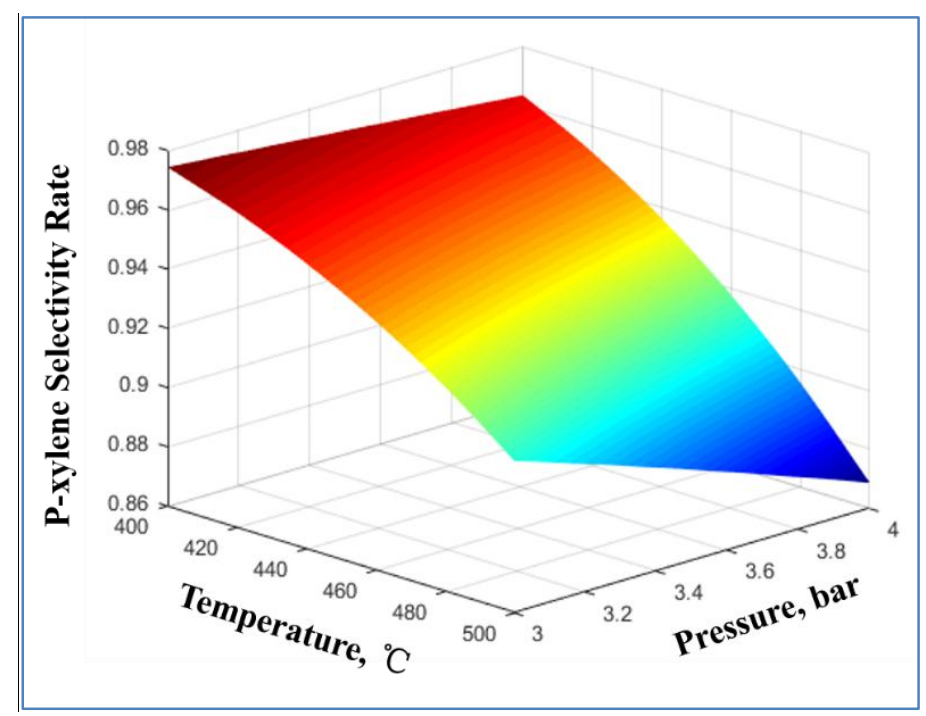

Figure 6 Effect of temperature and pressure on $p$-xylene selectivity when $m=2$

\section{PLEASE INSERT FIGURE 7 HERE}

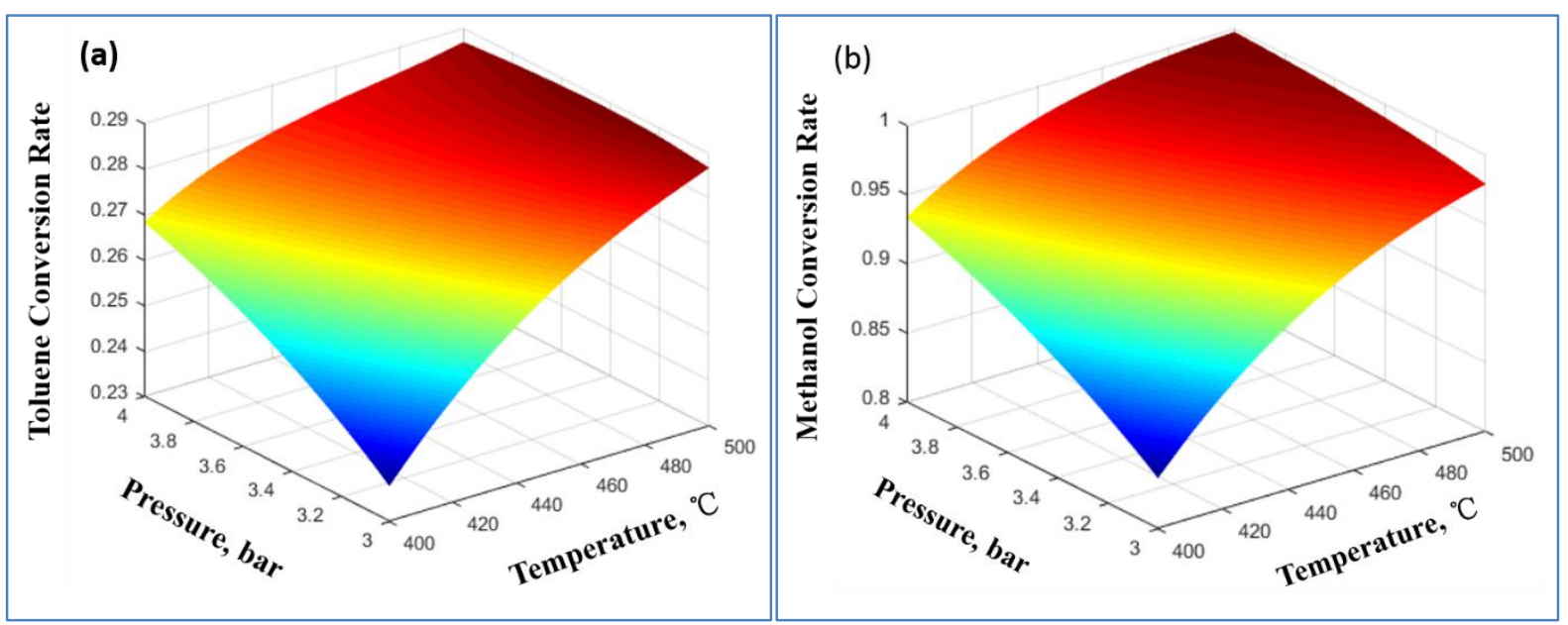

Figure 7 Effect of temperature and pressure on: (a) toluene conversion rate and (b) methanol conversion rate when $m=2$

As shown in Figure 6, the selectivity of $p$-xylene decreases along with the increase in temperature and pressure. When the temperature is $500.0{ }^{\circ} \mathrm{C}$ and the pressure is 4.0 bar, the selectivity of $p$-xylene reaches only around $85.0 \%$, and the remaining $15.0 \%$ are isomerization products (i.e., $o$-xylene and $m$-xylene). However, as the temperature decreases to $400.0{ }^{\circ} \mathrm{C}$ and the pressure changes to 3.0 bar, the selectivity of $p$-xylene can achieve above 97.0\%. From Figure 7a, the toluene conversion rate increases with the increase of 
temperature and pressure, demonstrating both temperature and pressure are key factors in toluene alkylation. It can be seen from Figure $7 \mathrm{~b}$ that the methanol conversion rate increases with the increase of the temperature and pressure and can reach $99.9 \%$ at $500.0{ }^{\circ} \mathrm{C}$ and 4.0 bar. Therefore, it can be concluded that the main reaction involving toluene alkylation, the isomerization of $p$-xylene, and the conversion of methanol to hydrocarbons prefer high temperature and pressure.

Based on the above analysis, the lower and upper bounds of the operating temperature, pressure and toluene-to-methanol feed ratio, $m$, are thus obtained, as shown in Table 6.

\section{PLEASE INSERT TABLE 6 HERE}

Table 6 Lower and upper bounds of toluene-to-methanol feed ratio, temperature and pressure

\begin{tabular}{lll}
\hline operating variables & lower bounds & upper bounds \\
\hline temperature, ${ }^{\circ} \mathrm{C}$ & 400.0 & 500.0 \\
pressure, bar & 3.0 & 4.0 \\
toluene-to-methanol feed ratio, $m$ & 1 & 4 \\
\hline
\end{tabular}

The optimization model PM is solved using SQP optimization solver implemented in Aspen Plus on a desktop with Intel(R) Core(TM) i7-4790 CPU @ 3.60GHz, 8 GB memory. The optimal values are obtained within 5 minutes and they are listed in Table 7.

\section{PLEASE INSERT TABLE 7 HERE}

Table 7 Optimal operating conditions for the reactor

\begin{tabular}{lccccccc}
\hline & $\mathrm{T},{ }^{\circ} \mathrm{C}$ & $\mathrm{P}$, bar & Space time, $\mathrm{W} / \mathrm{F}_{\mathrm{T}},(\mathrm{g} \mathrm{h}) / \mathrm{mol}$ & $m$ & $\mathrm{~S}_{\mathrm{p}-\mathrm{X}}$ & ${ }^{\mathrm{a}} \mathrm{C}_{\mathrm{T}}$ & ${ }^{\mathrm{a}} \mathrm{C}_{\mathrm{M}}$ \\
\hline Base case & 400.0 & 3.0 & 2.5 & 2.0 & 97.7 & 23.0 & 65.5 \\
optimized & 442.5 & 4.0 & 3.4 & 1.8 & 92.0 & 28.2 & 98.0 \\
& ${ }^{\mathrm{a}} \mathrm{C}_{\mathrm{T}}$ represents toluene conversion and $\mathrm{C}_{\mathrm{M}}$ represents methanol conversion. & & \\
\hline
\end{tabular}

For a fair comparison, the production rate of $p$-xylene is maintained at $179.0 \mathrm{kmol} / \mathrm{h}$ in the proposed process, which is the same as the base case. After optimization, the reduced loss 
of toluene is sent back to the alkylation reactor and the conversion of toluene is increased, so that the amount of $p$-xylene can be kept same with that in base process although lower selectivity as compared with the base process. Meanwhile, in the existing process, the feed methanol for the alkylation reactor consists of two parts: one part is amount of $107.0 \mathrm{koml} / \mathrm{h}$ methanol that recovered from distillation system, the other part is amount of $393.0 \mathrm{koml} / \mathrm{h}$ fresh methanol to maintain a quantitative $p$-xylene production. However, in the optimized process, a complete reaction of methanol took place in the alkylation reactor, only a flowrate of $393.0 \mathrm{kmol} / \mathrm{h}$ fresh methanol is needed to maintain the same $p$-xylene production.

\subsection{The optimal p-xylene production process}

The flow diagram for the optimal p-xylene process with methanol conversion of $98.0 \%$ is illustrated in Figure 8. The detailed stream information is given in Table 8. The mixture of methanol and toluene is fed at $442.5{ }^{\circ} \mathrm{C}$ and 4.0 bar to reactor $\mathrm{R}-101$. Methanol is almost completely converted in reactor R-101 compared to the base case. Trace amount of methanol in the bottom of the flash tank is fed to decanter D-101. Since methanol does not appear in the water-rich phase, methanol recovery system is not required. In addition, the flow rate of recycle stream S-18 is $512.0 \mathrm{kmol} / \mathrm{h}$ and the toluene fresh feed is set at $215.0 \mathrm{kmol} / \mathrm{h}$ (i.e., recycle-to-feed ratio $=2.38$ ) to maintain a quantitative yield of $p$-xylene. The rest of the process in Figure 8 is the same as the base case in Figure 4. Eventually, a flow rate of 179.0 $\mathrm{kmol} / \mathrm{h} p$-xylene product with a purity of $99.7 \mathrm{wt} \%$ is obtained. In addition, in the benzene distillation column (T-101), less than $0.06 \%$ of toluene is found in the top liquid product without recovery, whilst it is more than $1.18 \%$ in Figure 4 (the existing process ${ }^{15}$ ). The reason is not because of improper design of the distillation column in Ashraf et al. ${ }^{15}$, but because the 
conversion rate of toluene in the $p$-xylene reactor of the existing process is lower than the optimal process resulting in a larger load of toluene in distillation process.

\section{PLEASE INSERT TABLE 8 HERE}

Table 8 Stream data for $\mathrm{p}$-xylene production from the optimized process

\begin{tabular}{|c|c|c|c|c|c|c|c|c|}
\hline Stream & & S-1 & S-2 & S-7 & S-8 & GAS-1 & S-12 & GAS-2 \\
\hline mole flow & $\mathrm{kmol} / \mathrm{h}$ & 215.24 & 393.00 & 1132.74 & 1226.93 & 96.87 & 750.58 & 8.61 \\
\hline mass flow & $\mathrm{kg} / \mathrm{h}$ & 19832.30 & 12592.60 & 80633.10 & 80633.10 & 2728.20 & 70932.70 & 252.59 \\
\hline vapor fraction & & 0.00 & 0.00 & 1.00 & 1.00 & 1.00 & 0.00 & 0.00 \\
\hline temperature & ${ }^{\circ} \mathrm{C}$ & 25.00 & 25.00 & 240.00 & 442.50 & 25.00 & 21.00 & 42.44 \\
\hline pressure & bar & 1.00 & 1.00 & 4.00 & 4.00 & 1.10 & 8.20 & 8.00 \\
\hline \multicolumn{9}{|c|}{ Component Mole Flow } \\
\hline Toluene & $\mathrm{kmol} / \mathrm{h}$ & 215.24 & 0.00 & 727.29 & 515.56 & 1.82 & 513.69 & 0.00 \\
\hline Methanol & $\mathrm{kmol} / \mathrm{h}$ & 0.00 & 393.00 & 393.00 & 8.40 & 0.12 & 2.09 & 0.09 \\
\hline $\mathrm{p}-\mathrm{X}$ & $\mathrm{kmol} / \mathrm{h}$ & 0.00 & 0.00 & 1.90 & 189.58 & 0.23 & 189.34 & 0.00 \\
\hline Water & $\mathrm{kmol} / \mathrm{h}$ & 0.00 & 0.00 & 0.00 & 384.60 & 13.50 & 2.23 & 0.15 \\
\hline Benzene & $\mathrm{kmol} / \mathrm{h}$ & 0.00 & 0.00 & 10.49 & 18.24 & 0.20 & 18.03 & 0.24 \\
\hline GH & $\mathrm{kmol} / \mathrm{h}$ & 0.00 & 0.00 & 0.00 & 94.19 & 80.97 & 8.84 & 8.13 \\
\hline$m-X$ & $\mathrm{kmol} / \mathrm{h}$ & 0.00 & 0.00 & 0.06 & 8.21 & 0.01 & 8.20 & 0.00 \\
\hline$o-X$ & $\mathrm{kmol} / \mathrm{h}$ & 0.00 & 0.00 & 0.01 & 8.16 & 0.01 & 8.15 & 0.00 \\
\hline TBB & $\mathrm{kmol} / \mathrm{h}$ & 0.00 & 0.00 & 0.00 & 0.00 & 0.00 & 0.00 & 0.00 \\
\hline DTBB & $\mathrm{kmol} / \mathrm{h}$ & 0.00 & 0.00 & 0.00 & 0.00 & 0.00 & 0.00 & 0.00 \\
\hline TBMX & $\mathrm{kmol} / \mathrm{h}$ & 0.00 & 0.00 & 0.00 & 0.00 & 0.00 & 0.00 & 0.00 \\
\hline Stream name & & S-14 & S-17 & S-19 & $S$ & $\mathrm{~W}$ & B & $\mathrm{PX}$ \\
\hline mole flow & $\mathrm{kmol} / \mathrm{h}$ & 750.6 & 205.08 & 524.50 & 6.00 & 23.57 & 8.50 & 179.00 \\
\hline mass flow & $\mathrm{kg} / \mathrm{h}$ & 70932.7 & 21753.30 & 48208.20 & 914.54 & 2951.12 & 716.70 & 19003.00 \\
\hline vapor fraction & & 0.00 & 0.00 & 1.00 & 0.00 & 1.00 & 0.00 & 0.00 \\
\hline temperature & ${ }^{\circ} \mathrm{C}$ & 21.09 & 184.25 & 240.00 & 150.00 & 156.19 & 59.00 & 109.05 \\
\hline pressure & bar & 8.20 & 3.00 & 4.00 & 1.50 & 1.06 & 0.40 & 0.43 \\
\hline \multicolumn{9}{|c|}{ Component Mole Flow } \\
\hline Toluene & $\mathrm{kmol} / \mathrm{h}$ & 513.59 & 1.35 & 512.05 & 0.00 & 0.00 & 1.28 & 0.07 \\
\hline Methanol & $\mathrm{kmol} / \mathrm{h}$ & 2.09 & 0.00 & 0.00 & 0.00 & 0.00 & 0.00 & 0.00 \\
\hline $\mathrm{p}-\mathrm{X}$ & $\mathrm{kmol} / \mathrm{h}$ & 189.34 & 187.44 & 1.90 & 0.00 & 7.84 & 1.24 & 178.37 \\
\hline Water & $\mathrm{kmol} / \mathrm{h}$ & 2.23 & 0.00 & 0.00 & 0.00 & 0.00 & 0.00 & 0.00 \\
\hline Benzene & $\mathrm{kmol} / \mathrm{h}$ & 18.03 & 0.00 & 10.48 & 0.00 & 0.00 & 5.98 & 0.00 \\
\hline GH & $\mathrm{kmol} / \mathrm{h}$ & 8.84 & 0.00 & 0.00 & 0.00 & 0.00 & 0.00 & 0.00 \\
\hline $\mathrm{m}-\mathrm{X}$ & $\mathrm{kmol} / \mathrm{h}$ & 8.20 & 8.14 & 0.06 & 0.10 & 0.15 & 0.00 & 0.02 \\
\hline $0-X$ & $\mathrm{kmol} / \mathrm{h}$ & 8.15 & 8.14 & 0.01 & 0.00 & 7.60 & 0.00 & 0.50 \\
\hline TBB & $\mathrm{kmol} / \mathrm{h}$ & 0.00 & 0.00 & 0.00 & 4.00 & 0.01 & 0.00 & 0.00 \\
\hline DTBB & $\mathrm{kmol} / \mathrm{h}$ & 0.00 & 0.00 & 0.00 & 2.00 & 0.01 & 0.00 & 0.00 \\
\hline TBMX & $\mathrm{kmol} / \mathrm{h}$ & 0.00 & 0.00 & 0.00 & 0.00 & 7.97 & 0.00 & 0.00 \\
\hline
\end{tabular}




\section{PLEASE INSERT FIGURE 8 HERE}

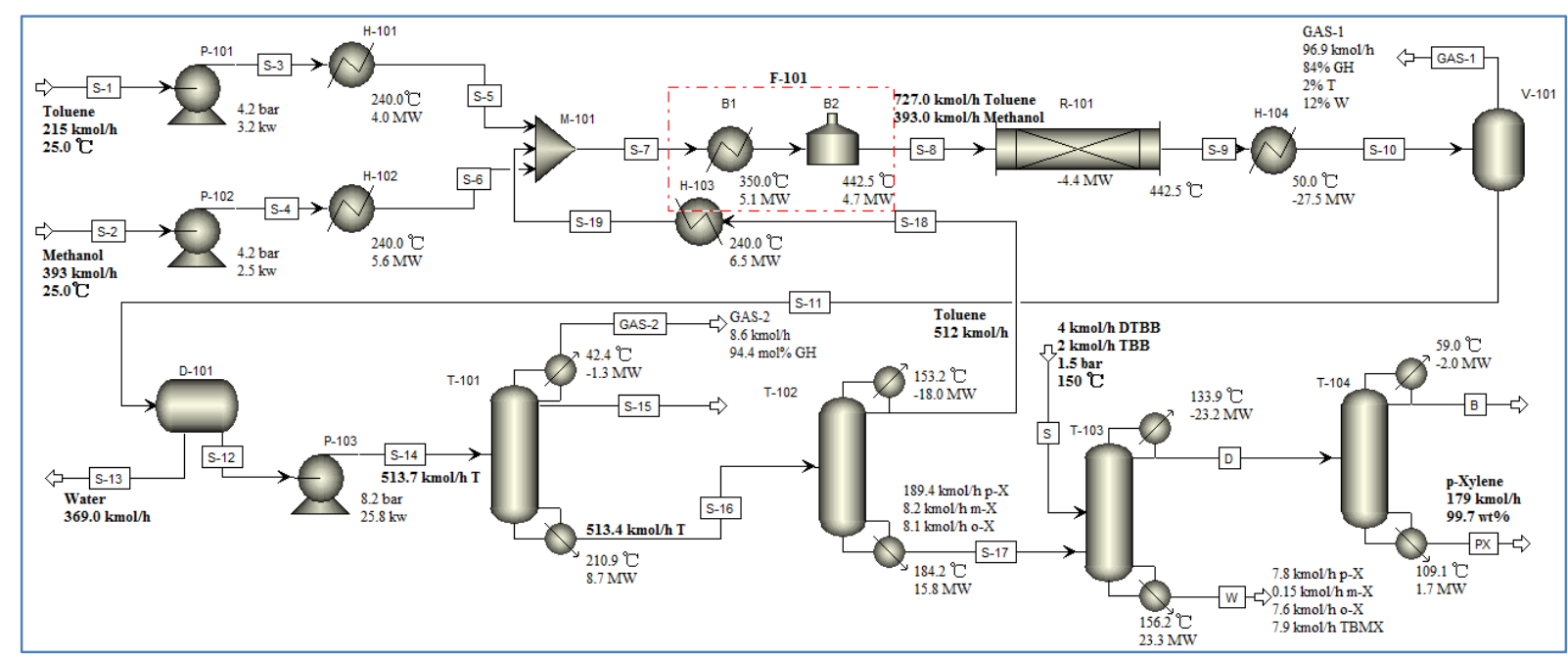

Figure 8 Process flow diagram for the proposed p-xylene production with almost complete methanol conversion

The detailed economic evaluation results for the proposed $p$-xylene production process in Figure 8 are provided in Table 9.

\section{PLEASE INSERT TABLE 9 HERE}

Table 9 Economic evaluation results for the proposed $p$-xylene production process

\begin{tabular}{lllll}
\hline equipment & comments & value & IC $(\mathrm{k} \$)$ & OC (k\$/year) \\
\hline P-101 & toluene pump & 3.2 & 43.9 & 2.1 \\
P-102 & methanol pump & 2.5 & 42.8 & 1.7 \\
P-103 & feed pump & 25.8 & 57.4 & 18.4 \\
H-101 (MW) & heater & 4.0 & 200.7 & 1120.7 \\
H-102 (MW) & heater & 5.6 & 215.1 & 1577.5 \\
H-103 (MW) & heater & 6.5 & 371.6 & 1831.0 \\
H-104 (MW) & condenser & 27.5 & 361.8 & 78.5 \\
F-101 (MW) & fired furnace & 9.7 & 1432.9 & 2825.6 \\
R-101 (MW) & alkylation reactor & 4.4 & 421.2 & 12.5 \\
V-101 & flash vessel & - & 173.3 & - \\
D-101 & decanter & - & 173.0 & - \\
T-101 ( $\left.{ }^{\mathrm{a} C / R}, \mathrm{MW}\right)$ & benzene distillation column & $1.3 / 8.7$ & 1381.5 & 2431.0 \\
$\mathrm{~T}-102\left({ }^{\mathrm{a}} \mathrm{C} / \mathrm{R}, \mathrm{MW}\right)$ & toluene distillation column & $18.0 / 15.8$ & 2044.4 & 4483.1 \\
$\mathrm{~T}-103\left({ }^{\mathrm{a}} \mathrm{C} / \mathrm{R}, \mathrm{MW}\right)$ & reaction distillation column & $23.2 / 23.3$ & 4981.5 & 5300.5 \\
$\mathrm{~T}-104\left({ }^{\mathrm{a} C} / \mathrm{R}, \mathrm{MW}\right)$ & p-xylene distillation column & $1.7 / 1.4$ & 1112.7 & 386.2 \\
total cost & - & - & 13013.8 & 20068.8 \\
${ }^{\mathrm{a} C}$ represents Condenser and R represents Reboiler & & & \\
\hline
\end{tabular}


Similarly, in Table 9, we also can find that there is such a significant difference between the condenser and reboiler duties of the benzene distillation column (T-101), the main reason for this is the same as the benzene distillation column (T-102) in section 4.1. In addition, we also compare the economics of the proposed $p$-xylene production process with the base case (i.e., existing process ${ }^{15}$ ). The main results about heaters and distillation columns are presented in Table 10. The total capital cost (TCI) and total operating cost (TOC) are significantly reduced by $17.3 \%$ and $21.8 \%$, respectively compared to those of the base case. This is mainly because of the removal of methanol recovery and recycles system, and the reduction of toluene recycle amount.

\section{PLEASE INSERT TABLE 10 HERE}

Table 10 Comparative results for the base case and the proposed process

\begin{tabular}{llllll}
\hline \multirow{2}{*}{ type } & \multicolumn{3}{c}{$\begin{array}{c}\text { base case } \\
\left.\text { (the existing process }{ }^{15}\right)\end{array}$} & & \multicolumn{2}{c}{ the proposed process } \\
\cline { 2 - 3 } \cline { 5 - 6 } & TCI $(\mathrm{k} \$)$ & TOC $(\mathrm{k} \$$ /year) & & TCI $(\mathrm{k} \$)$ & TOC $(\mathrm{k}$ \$/year $)$ \\
\hline pumps & 223.1 & 30.8 & & 144.1 & 22.2 \\
heaters & 2473.9 & 9027.0 & & 2582.1 & 7433.3 \\
distillation columns & 12448.0 & 16591.9 & & 9520.1 & 12600.8 \\
other units & 586.3 & 11.7 & & 767.5 & 12.5 \\
total & 15731.3 & 204687.2 & & 13013.8 & 19094.6 \\
savings $(\%)$ & & & 17.3 & 21.8 \\
\hline
\end{tabular}

\subsection{Heat Integration}

As seen from Figure 8, the reactor outlet flow in the proposed process (see Figure 8) can provide 27.5 MW of energy without effective utilization. To improve energy efficiency of the proposed process and reduce the operating cost further, heat integration is conducted using Aspen Energy Analysis ${ }^{40,41}$, which is based on pinch analysis method. The heat exchanger network (HEN) is automatically created based on the pinch analysis using Aspen Energy 
Analysis. ${ }^{42-44}$ The minimum temperature approach, $\Delta T_{\min }$ is assumed to be $10.0{ }^{\circ} \mathrm{C}$.

4.4.1 HEN for the proposed process. The data on hot and cold streams in the proposed process are listed in Table 11. The composite curve of cold and hot streams in the proposed process is shown in Figure 9.

\section{PLEASE INSERT FIGURE 9 HERE}

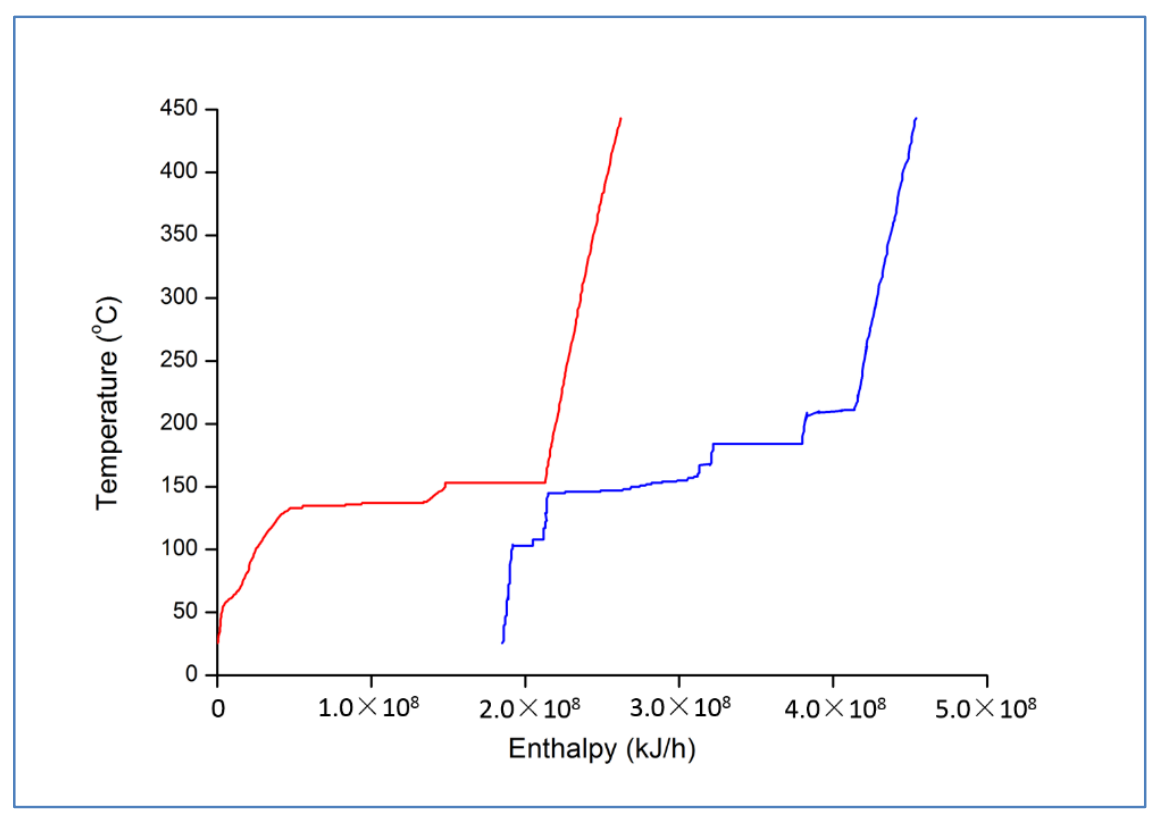

Figure 9 The composite curve of cold and hot logistics in the proposed process

\section{PLEASE INSERT TABLE 11 HERE}

Table 11 Thermodynamic data of hot and cold streams in the proposed process

\begin{tabular}{lcccc}
\hline \multirow{2}{*}{ stream } & $\begin{array}{c}\text { inlet temperature, outlet temperature, } \\
{ }^{\circ} \mathrm{C}\end{array}$ & $\begin{array}{c}\text { heat duty, } \\
\mathrm{kJ} / \mathrm{h}\end{array}$ & $\begin{array}{c}\mathrm{MCp}, \\
\mathrm{kJ} /{ }^{\circ} \mathrm{C} \mathrm{h}\end{array}$ \\
\hline S-9_To_S-10 & 442.5 & 50.0 & $9.917 \times 10^{7}$ & $4.123 \times 10^{5}$ \\
S-3_To_S-5 & 25.0 & 240.0 & $1.440 \times 10^{7}$ & $2.882 \times 10^{7}$ \\
S-4_To_S-6 & 25.0 & 240.0 & $2.026 \times 10^{7}$ & $9.078 \times 10^{7}$ \\
S-18_To_S-19 & 153.2 & 240.0 & $2.352 \times 10^{7}$ & $1.190 \times 10^{6}$ \\
S-7_To_S-8 & 240.0 & 442.5 & $3.533 \times 10^{7}$ & $1.749 \times 10^{5}$ \\
V-101_heat & 50.0 & 25.0 & $3.522 \times 10^{6}$ & $1.409 \times 10^{5}$ \\
To Condenser@T-101_TO_GAS-2 & 147.2 & 42.4 & $4.588 \times 10^{6}$ & $8.737 \times 10^{4}$ \\
To Reboiler@T-101_TO_S-16 & 209.0 & 210.9 & $3.118 \times 10^{7}$ & $1.614 \times 10^{7}$ \\
To Condenser@T-102_TO_S-18 & 153.7 & 153.2 & $6.476 \times 10^{7}$ & $1.310 \times 10^{8}$ \\
To Reboiler@T-102_TO_S-17 & 184.0 & 184.2 & $5.692 \times 10^{7}$ & $3.040 \times 10^{8}$ \\
To Condenser@T-103_TO_D & 137.0 & 133.9 & $8.268 \times 10^{7}$ & $4.246 \times 10^{7}$ \\
\hline
\end{tabular}




\begin{tabular}{lcccc}
\hline To Reboiler@T-103_TO_W & 145.7 & 156.2 & $8.041 \times 10^{7}$ & $1.150 \times 10^{7}$ \\
To Condenser@T-104_TO_B & 73.7 & 59.0 & $7.236 \times 10^{6}$ & $5.789 \times 10^{5}$ \\
To Reboiler@T-104_TO_PX & 108.9 & 109.1 & $6.174 \times 10^{6}$ & $7.391 \times 10^{7}$ \\
\hline
\end{tabular}

\section{PLEASE INSERT FIGURE 10 HERE}

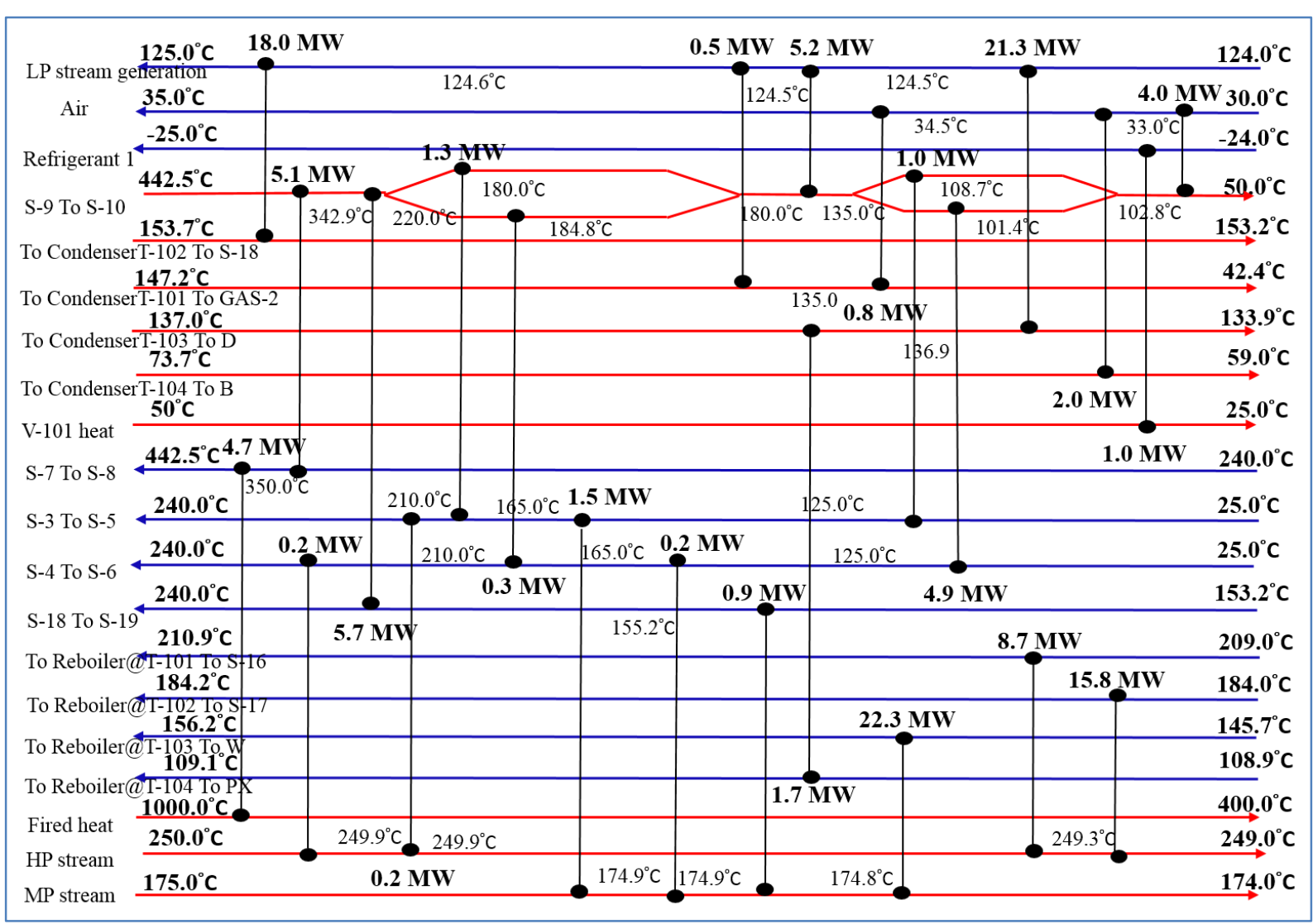

Figure 10 The HEN diagram from the proposed $p$-xylene production process after heat integration

The HEN diagram from the proposed $p$-xylene production process is illustrated in Figure 10. As shown in Figure 10, the reactor effluent (i.e., S9) is first used to preheat the inlet stream (S-7) of the combustion furnace from $240{ }^{\circ} \mathrm{C}$ to $350.0{ }^{\circ} \mathrm{C}$, resulting in significant energy reduction in the furnace from 9.7 $\mathrm{MW}$ to $4.7 \mathrm{MW}$. The surplus low-temperature heat is then used to provide energy for fresh and recycle streams (S-3, S-4, and S-18) and produce LP steam. As shown in the figure, the remaining heat energy in this stream (S-9) first supplies energy to the recycle stream because the recycle stream requires a relatively large number of 
heat and then partially heats up the fresh stream. The thermal coupling of coolers with the reboilers in $p$-xylene separation process also could reduce the energy consumption. The top vapor from T-103 (S-D) is used to provide energy for the reboiler of T-104 (S-PX). After heat integration, the operating cost is decreased by $3123.9 \mathrm{k} \$ /$ year compared to that in Figure 8 without heat integration.

4.4.2 HEN for the base case. To fairly compare with the base case, we also conduct heat integration for the base in Figure 4. The hot and cold streams for the base case are given in Table 12. The composite curve is illustrated in Figure 11.

\section{PLEASE INSERT FIGURE 11 HERE}

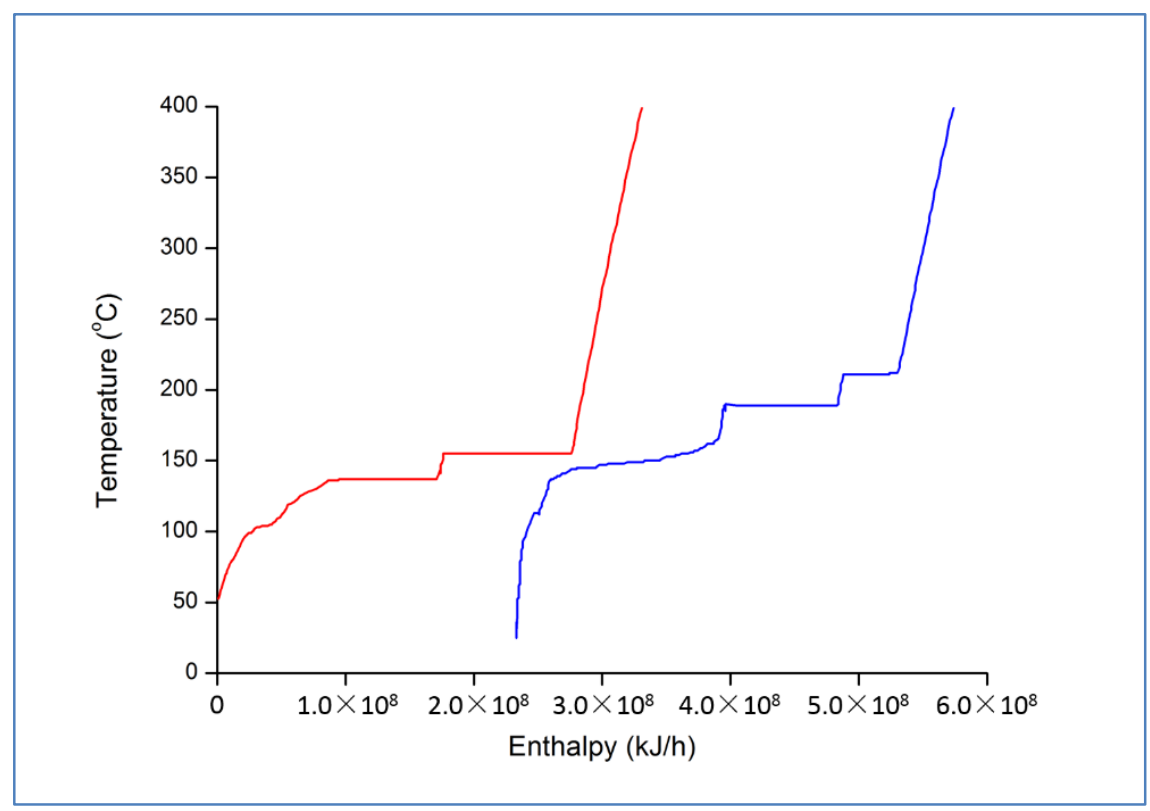

Figure 11 The composite curve of cold and hot logistics in the existing process

\section{PLEASE INSERT TABLE 12 HERE}

Table 12 Thermodynamic data for hot and cold streams in the existing process

\begin{tabular}{lcccc}
\hline stream & $\begin{array}{c}\text { inlet temperature outlet temperature } \\
{ }^{\circ} \mathrm{C}\end{array}$ & $\begin{array}{c}\text { heat duty, } \\
\mathrm{kJ} / \mathrm{h}\end{array}$ & $\begin{array}{c}\mathrm{MCp}, \\
\mathrm{kJ} /{ }^{\circ} \mathrm{C} \mathrm{h}\end{array}$ \\
\hline S-9_To_S-10 & 400.0 & 50.0 & $1.245 \times 10^{8}$ & $6.409 \times 10^{5}$ \\
S-22_To_S-23 & 136.1 & 240.0 & $4.157 \times 10^{7}$ & $1.804 \times 10^{6}$ \\
S-3_To_S-5 & 25.0 & 240.0 & $1.444 \times 10^{7}$ & $2.112 \times 10^{5}$ \\
\hline
\end{tabular}




\begin{tabular}{lcccc}
\hline S-4_To_S-6 & 25.0 & 240.0 & $2.016 \times 10^{7}$ & $4.840 \times 10^{5}$ \\
S-7_To_S-8 & 240.0 & 400.0 & $3.733 \times 10^{7}$ & $2.337 \times 10^{5}$ \\
To Condenser@T-101_TO_GAS-2 & 105.8 & 70.8 & $1.211 \times 10^{7}$ & $1.955 \times 10^{6}$ \\
To Reboiler@T-101_TO_S-17 & 145.8 & 145.9 & $1.437 \times 10^{7}$ & $2.376 \times 10^{8}$ \\
To Condenser@T-102_TO_GAS-3 & 142.8 & 74.2 & $9.824 \times 10^{6}$ & $2.880 \times 10^{5}$ \\
To Reboiler@T-102_TO_S-19 & 211.5 & 212.7 & $4.253 \times 10^{7}$ & $3.760 \times 10^{7}$ \\
To Condenser@T-103_TO_S-20 & 156.4 & 156.0 & $9.906 \times 10^{7}$ & $2.350 \times 10^{8}$ \\
To Reboiler@T-103_TO_S-21 & 188.8 & 189.0 & $8.818 \times 10^{7}$ & $8.000 \times 10^{8}$ \\
To Condenser@T-104_TO_D & 137.8 & 136.9 & $8.168 \times 10^{7}$ & $1.540 \times 10^{8}$ \\
To Reboiler@T-104_TO_W & 147.4 & 164.7 & $7.940 \times 10^{7}$ & $6.576 \times 10^{6}$ \\
To Condenser@T-105_TO_B & 107.3 & 92.8 & $3.315 \times 10^{6}$ & $3.088 \times 10^{5}$ \\
To Reboiler@T-105_TO_PX & 113.8 & 113.9 & $2.345 \times 10^{6}$ & $3.261 \times 10^{7}$ \\
\hline
\end{tabular}

\section{PLEASE INSERT FIGURE 12 HERE}

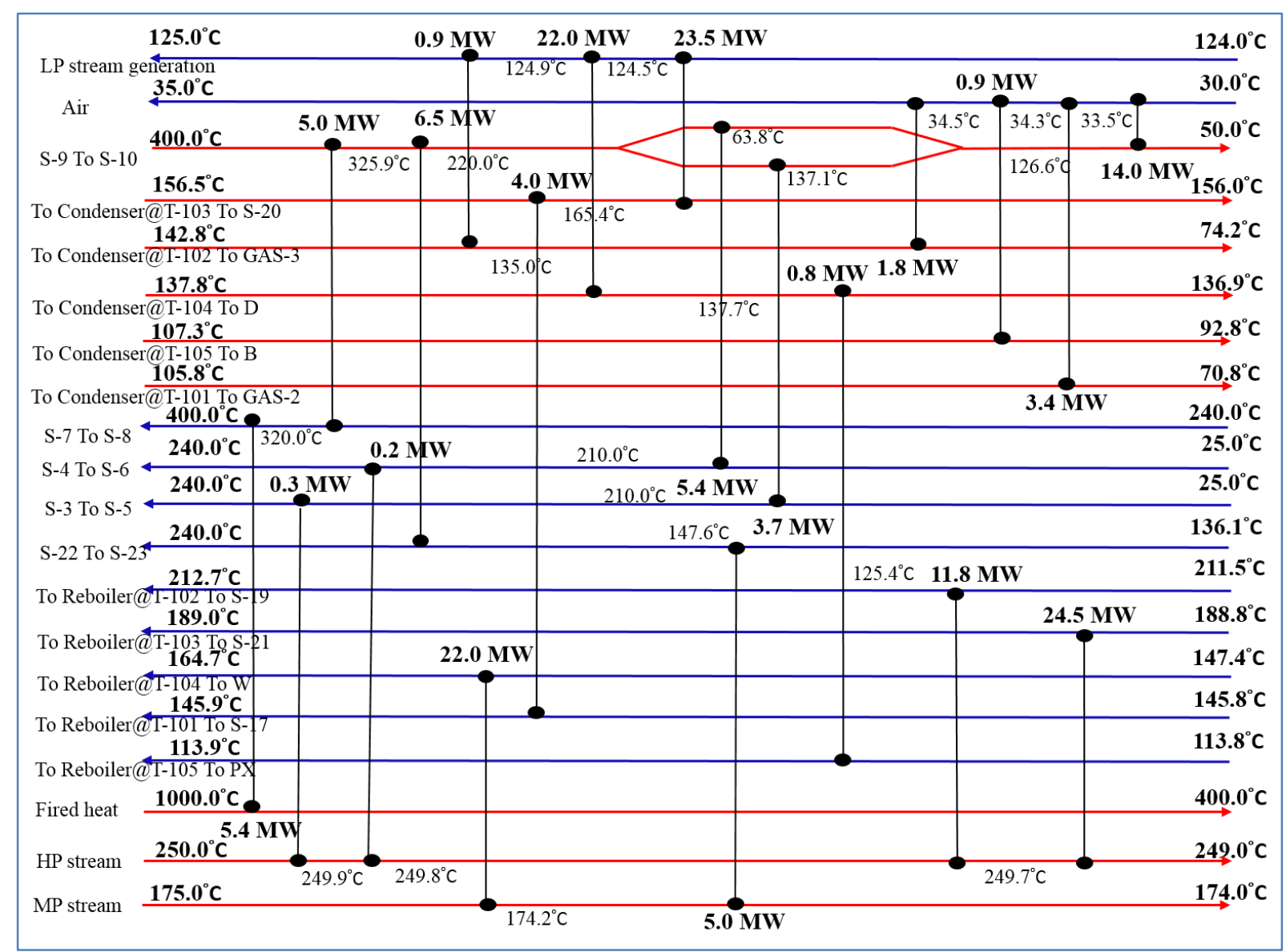

Figure 12 The HEN diagram for the existing $p$-xylene production process

Figure 12 illustrates the HEN diagram from the base case (i.e., the existing $p$-xylene production process). From Figure 12, it can be observed that the reactor effluent is first 
utilized to heat up the stream (S-7) to the temperature of $320.0{ }^{\circ} \mathrm{C}$ before the inlet of the furnace, and reducing the energy consumption of the furnace from 10.4 MW to 5.4 MW. the surplus energy is utilitzed for preheating fresh and recycle streams ( $\mathrm{S}-3, \mathrm{~S}-4$, and S-22). In addition, the top vapor from $\mathrm{T}-103$ and $\mathrm{T}-104$ are utilized to provide energy for the reboilers of T-101 and T-105, respectively. After heat integration, the operating cost is decreased by $1846.5 \mathrm{k} \$$ /year compared to the reference process in Figure 4 without heat integration.

\title{
4.5 Overall economic and environmental impacts
}

The overall economic and environmental impacts are summarized in Table 13. The Environmental impact is based on indirect $\mathrm{CO}_{2}$ emissions, which mainly correspond to electricity and thermal energy consumption in the $p$-xylene production process. Note that the electricity consumption is negligible compared to the thermal energy consumption in the process. The $\mathrm{CO}_{2}$ emissions associated with thermal energy consumption is assumed to be $8.87 \times 10^{8}$ ton $\mathrm{CO}_{2} / \mathrm{kJ} \cdot{ }^{35}$

As shown in Table 13, the TOC for the proposed process is further reduced by $15.6 \%$ after heat integration, whilst it for the existing process is about $7.2 \%$ after heat integration. The overall total annual cost (TAC) value of the existing process and the proposed process are calculated using eq. 19. The TAC for the proposed process after heat integration is reduced by $4.71 \%$ compared to the existing process without heat integration.

\author{
PLEASE INSERT TABLE 13 HERE
}


Table 13 Comparative results on economic and environmental impacts for the proposed process and the existing process

\begin{tabular}{|c|c|c|c|c|c|}
\hline \multirow[t]{2}{*}{ type } & \multicolumn{2}{|c|}{ before heat integration } & \multicolumn{2}{|c|}{ after heat integration } & \multirow[b]{2}{*}{ savings } \\
\hline & $\begin{array}{c}\text { the existing } \\
\text { process }\end{array}$ & $\begin{array}{c}\text { the proposed } \\
\text { process }\end{array}$ & $\begin{array}{c}\text { the existing } \\
\text { process }\end{array}$ & $\begin{array}{c}\text { the proposed } \\
\text { process }\end{array}$ & \\
\hline TIC (k\$) & 15731.3 & 13013.8 & 16121.5 & 12668.2 & - \\
\hline TOC (k\$/year) & 25661.4 & 20068.8 & 23814.9 & 16945.0 & \\
\hline RMC (k\$/year) & 175961.0 & 175961.0 & 175961.0 & 175961.0 & - \\
\hline TAC (k\$/year) & 206866.2 & 200367.7 & 205149.7 & 197128.7 & $4.71 \%$ \\
\hline heating duty $(\mathrm{kJ} / \mathrm{h})$ & $3.404 \times 10^{8}$ & $2.678 \times 10^{8}$ & $2.494 \times 10^{8}$ & $1.964 \times 10^{8}$ & - \\
\hline cooling duty $(\mathrm{kJ} / \mathrm{h})$ & $3.305 \times 10^{8}$ & $2.616 \times 10^{8}$ & $2.396 \times 10^{8}$ & $1.902 \times 10^{8}$ & - \\
\hline $\begin{array}{l}\mathrm{CO}_{2} \text { emissions } \\
\left(\mathrm{tCO}_{2} / \mathrm{t}_{\text {p-xylene }}\right)\end{array}$ & 1.54 & 1.25 & 1.15 & 0.92 & $40.2 \%$ \\
\hline toluene loss (\%) & 1.18 & 0.06 & - & - & - \\
\hline
\end{tabular}

It can be also concluded that significant reduction of $\mathrm{CO} 2$ emissions is achieved using the proposed process, which is $40.2 \%$ less than that using the existing process. This is mainly because of the removal of the methanol recovery column, decreasing recycled quality of toluene using the proposed $p$-xylene process and heat integration. It should be mentioned that the Toluene loss in the benzene column for the proposed process is much lower than that in the existing process.

\section{Conclusions}

In this work, an intensified $p$-xylene production process through toluene alkylation was proposed and a systematic design procedure was proposed including thermodynamic and kinetic insight analysis, process simulation, sensitivity analysis, and optimization through Sequential Quadratic Programming tool implemented in Aspen Plus. It was found that the methanol conversion could reach $98.0 \%$ with $p$-xylene selectivity of $92.0 \%$ when the operating temperature reached $442.5{ }^{\circ} \mathrm{C}$, the pressure was about 4 bar and the toluene-to-methanol feed ratio was 1.8 . Such $p$-xylene production process led to the removal of methanol recovery column, less toluene loss, and much less recycle toluene in the 
downstream. After heat integration, the proposed $p$-xylene process could achieve a reduction of $4.71 \%$ in overall TAC and of $40.2 \%$ in $\mathrm{CO}_{2}$ emissions compared to the existing $p$-xylene process without heat integration. The proposed $p$-xylene process provides an alternative way for $p$-xylene production, which is more sustainable. In the future, sensitivity analysis on the effect of the variations in the optimal operating conditions on the process performance will be investigated and efficient process control system will be proposed to guarantee the operating parameters are well controlled to be or close to the set-points when variations in the optimal operating conditions occur.

\section{Acknowledgment}

We acknowledge the financial support provided by the National Natural Science Foundation of China (No. 21878028, 21606026); the Fundamental Research Funds for the Central Universities (No. 106112017CDJQJ228809); Chongqing Research Program of Basic Research and Frontier Technology (No. CSTC2016JCYJA0474); and Hundred Talents Program of Chongqing University.

\section{Supporting Information}

The supporting Information is available free of charge via the Internet at http://pubs.acs.org/.

The detailed stream information of the existing process (base case) see in Table S1, these formulas of factor see in Eqs. S1-S4, and the iterative algorithm block diagram of calculating effectiveness diffusion coefficient De see in Figure S1. 


\section{Nomenclature}

$\mathrm{A}_{\mathrm{i}}=$ pre-exponential factor, $\mathrm{mol} /\left(\mathrm{g} \cdot \mathrm{h} \cdot \mathrm{atm}^{2}\right)$ or $\mathrm{mol} /(\mathrm{g} \cdot \mathrm{h} \cdot \mathrm{atm})$

$\mathrm{k}_{\mathrm{i}}=$ rate constant, $\mathrm{mol} /\left(\mathrm{g} \cdot \mathrm{h} \cdot \mathrm{atm}^{2}\right)$ or $\mathrm{mol} /(\mathrm{g} \cdot \mathrm{h} \cdot \mathrm{atm})$

$E_{i}=$ activation energy, $\mathrm{kJ} / \mathrm{mol}$

$\mathrm{De}=$ effectiveness diffusion coefficient, $\mathrm{m}^{2} / \mathrm{s}$

$\mathrm{p}=$ pressure, atm

$\mathrm{K}_{\mathrm{i}}^{\mathrm{R}}=$ equilibrium constant, -

$\mathrm{wt}=$ mass percent, $\%$

$\mathrm{S}_{\mathrm{p}}=p$-xylene selectivity, $\%$

$\mathrm{F}_{\mathrm{T}}=$ toluene molar flow rate, $\mathrm{kmol} / \mathrm{h}$

$\mathrm{F}_{\mathrm{M}}=$ methanol molar flow rate, $\mathrm{kmol} / \mathrm{h}$

$\mathrm{F}_{\mathrm{p}-\mathrm{X}}=p$-xylene molar flow rate, $\mathrm{kmol} / \mathrm{h}$

$\mathrm{F}_{\mathrm{m}-\mathrm{X}}=m$-xylene molar flow rate, $\mathrm{kmol} / \mathrm{h}$

$\mathrm{F}_{\mathrm{o}-\mathrm{X}}=o$-xylene molar flow rate, $\mathrm{kmol} / \mathrm{h}$

$\mathrm{W}=$ catalyst weight, $\mathrm{kg}$

\section{Subscripts}

$\mathrm{i}=$ reaction number

$\mathrm{T}=$ toluene

$\mathrm{M}=$ methanol

$m$-X $=m$-xylene

$o$-X $=o$-xylene

$p$-X $=p$-xylene

\section{Compounds}


$\mathrm{B}=$ benzene

DTBB = di-tert-butyl-benzene

$\mathrm{GH}=$ light gaseous hydrocarbons

$\mathrm{TBB}=$ tert-butyl-benzene

TBMX = tert-butyl $m$-xylene

15
16
17
18
19
20
21
22
23
24
25
26
27
28
29
30
31
32
33
34
35
36
37
38
39
40
41
42
43
44
45
46
47
48
49
50
51
52
53
54
55
56
57
58
59
60




\section{References}

1. Chadwick, S. S. Ullmann's Encyclopedia of Industrial Chemistry. Reference Services Review 1988, 16 (4), 31-34.

2. Meyers, R. A. Handbook of petroleum refining processes, 3rd ed. McGraw-Hill: 1986; p 8.

3. Maneffa, A.; Priecel, P.; Lopez-Sanchez, J. A. Biomass-Derived Renewable Aromatics: Selective Routes and Outlook for p-Xylene Commercialization. Chemsuschem. 2016, 9(19), 2736-2748.

4. Ouyang, Q.; Yin, S. F.; Chen, L.; Zhou, X. P.; Au, C. T. A new catalytic process for high-efficiency synthesis of p-xylene by methylation of toluene with $\mathrm{CH}_{3} \mathrm{Br}$. AIChE J. 2013, 59 (2), 532-540.

5. Kim, J. C.; Kim, T. W.; Kim, Y.; Ryoo, R.; Jeong, S. Y.; Kim, C. U. Mesoporous MFI Zeolites as High Performance catalysts for Diels-Alder Cycloaddition of Bio-derived Dimethylfuran and Ethylene to Renewable p-Xylene. Appl. Catal. B-Environ. 2017, 206, 490-500.

6. Dawagreh, A. K. M. A., Disproportionation of Toluene to Produce Benzene and, p-Xylene: A Review. J. Sci. Ind. Res. 2001, 60 (4), 319-327.

7. Mitra, B.; Kunzru, D. Enhancing p-xylene productivity for disproportionation of toluene in microstructured reactors. Chem. Eng. Process. 2013, 64 (2), 48-56.

8. Haag, W. O.; Olson, D. H. Selective disproportionation of toluene. US Patent 4097543, 1978.

9. Maher, G. F.; Nemeth, L. T. Liquid phase process for C8 alkylaromatic isomerization. US Patent 6872866, March 29, 2005.

10. Tsai, T. C.; Liu, S. B.; Wang, I. Disproportionation and transalkylation of alkylbenzenes over zeolite catalysts. Appl. Catal. A-Gen. 1999, 181(2), 355-398.

11. Moreira, M. A.; Ferreira, A. F. P.; Santos, J. C.; Loureiro, J. M.; Rodrigues, A. E. Hybrid Process for o- and p-Xylene Production in Aromatics Plants. Chem. Eng. Technol. 2015, 37(9), 1483-1492.

12. Lide, D. R. CRC Handbook of Chemistry and Physics, 92nd Edition. 2011, p3-550.

13. Faramawy, S., Selective Toluene-Methanol Alkylation over Modified ZSM-5 Zeolite Catalysts. Petrol. Sci. Technol. 1999, 17(3-4), 249-271.

14. Brown, S. H.; Mathias, M. F.; Ware, R. A.; Olson, D. H., Selective para-xylene production by toluene methylation. U.S. Patent 6504072 B1, January 7, 2003.

15. Ashraf, M. T.; Chebbi, R.; Darwish, N. A. Process of p-Xylene Production by Highly Selective Methylation of Toluene. Ind. Eng. Chem. Res. 2013, 52(38), 13730-13737.

16. Liu, H. Y.; Zhu, J.; Wang, Y. D.; Yu, O. B.; Xu, T. J. Effect of operating conditions on alkylation of toluene with methanol. Petrol. Sci. Technol. 2017, 35(2), 148-154.

17. Wang, C.; Zhang, Q.; Zhu, Y.; Zhang, D.; Chen, J.; Chiang, F. K. p-Xylene selectivity enhancement in methanol toluene alkylation by separation of catalysis function and shape-selective function. Molecular Catalysis 2017, 433, 242-249. 
18. Breen, J.; Burch, R.; Kulkarni, M.; Collier, P.; Golunski, S. Enhanced para-xylene selectivity in the toluene alkylation reaction at ultralow contact time. J. Am. Chem. Soc. 2005, 127(14), 5020-5021.

19. Breen, J. P.; Burch, R.; Kulkarni, M.; Mclaughlin, D.; Collier, P. J.; Golunski, S. E. Improved selectivity in the toluene alkylation reaction through understanding and optimising the process variables. Appl. Catal. A-Gen. 2007, 316(1), 53-60.

20. Sotelo, J. L.; Uguina, M. A.; And, J. L. V.; Serrano, D. P. Deactivation Kinetics of Toluene Alkylation with Methanol over Magnesium-Modified ZSM-5. Ind. Eng. Chem. Res. 1993, 35(4), 2548-2554.

21. Zhao, Y. Preparation of catalyst with high selectivity and high stability for para-xylene. PhD Thesis, Dalian University of Technology , 2011.

22. Li, Y.-G.; Xie, W.-H.; Yong, S. The acidity and catalytic behavior of Mg-ZSM-5 prepared via a solid-state reaction. Appl. Catal. A-Gen. 1997, 150(2), 231-242.

23. Wang, Q. X.; Chen G. Q. Studies of Mg-ZSM-5 Zeolite Catalyst: I. Preparation of Mg-ZSM-5 and It's Properties. Petrochemical Technology 1988, 17, 288-292.

24. Young, L. B.; Butter, S. A.; Kaeding, W. W. Shape selective reactions with zeolite catalysts. III. Selective in xylene isomerization, toluene-methanol alkylation, and toluene disproportionation over ZSM-5 zeolite catalysts. J. Catal. 1982, 13(45), 418-432.

25. Palomino, J.L.V. Alquilación de tolueno con metanol mediante catalizadores de zeolita ZSM-5 modificados. PhD Thesis, Complutense University of Madrid, 1991.

26. Mantha, R.; Bhatia, S.; Rao, M. S. Kinetics of deactivation of methylation of toluene over H-ZSM-5 and hydrogen mordenite catalysts. Ind. Eng. Chem. Res. 1991, 30(2), 281-286.

27. Bhat, Y. S.; Halgeri, A. B.; Praaada Rao, T.S.R. Kinetics of Toluene Alkylation with Methanolon HZSM-8ZeoliteCatalysts. Ind. Eng. Chem. Res. 1989, 28, 890-894.

28. Vayssilov, G.; Yankov, M.; Hamid, A. ChemInform Abstract: Para-Selective Alkylation of Toluene with Methanol over ZSM-5 Zeolites. A Kinetic Model. Appl. Catal. A-Gen. 1993, 94, 117-130.

29. Yang, H. S.; Tang, X. N.; Zhang B.; Shang S. Y.; And Guo Y. J. Optimization of toluene-methanol alkylation simulation. Computers and Applied Chemistry. 2016, 33(03), 269-272.

30. Venkataraman, S.; Chan, W. K.; Boston, J. F. Reactive distillation using ASPEN PLUS. Chem. Eng. Prog. 1990, 86(8), 45-54.

31. Saito, S.; Michishita, T.; Maeda, S. Separation of meta- and para-xylene mixture by distillation accompanied by chemical reactions. J. Chem. Eng. Jap. 1971, 4(1), 37-43.

32. Franck, H. G.; Stadelhofer, J. W. Industrial Aromatic Chemistry. Springer-Verlag. 1988.

33. Yang, A.; Lv, L. P.; Shen, W. F.; Dong, L. C.; Li, J.; Xiao, X. Optimal Design and Effective Control of the tert-Amyl Methyl Ether Production Process Using an Integrated Reactive Dividing Wall and Pressure Swing Columns. Ind. Eng. Chem. Res. 2017, 56, 14565-14581.

34. Turton, R. Analysis, Synthesis and Design of Chemical Processes: Pearson New International Edition. Prentice-Hall international series in the physical and chemical 
engineering sciences. 2003.

35. Alexander, M. N.; Onur, O.; Christodoulos, A. F. Production of benzene, toluene, and xylenes from natural gas via methanol: Process synthesis and global optimization. AIChE J. 2015, 62(5), 1531-1556.

36. Luyben, W. L. Principles and Case Studies of Simultaneous Design. Wiley \& Sons: 2011.

37. Li, W.; Zhu, J. L.; Hua-Bao, L. I.; Wang, Y. H. Thermodynamic analysis and calculation of alkylation of toluene with methanol. Chem. Eng. 2008, 36(10), 48-51.

38. Vu, D. V.; Miyamoto, M.; Nishiyama, N.; Egashira, Y.; Ueyama, K. Selective formation of para-xylene over H-ZSM-5 coated with polycrystalline silicalite crystals. J. Catal. 2006, 243(2), 389-394.

39. Ghiaci, M.; Abbaspur, A.; Arshadi, M.; Aghabarari, B. Internal versus external surface active sites in ZSM-5 zeolite: Part 2: Toluene alkylation with methanol and 2-propanol catalyzed by modified and unmodified $\mathrm{H}_{3} \mathrm{PO}_{4} /$ ZSM-5. Appl. Catal. A-Gen. 2007, 316(1), 32-46.

40. Cui, C.; Sun, J. Coupling design of interunit heat integration in an industrial crude distillation plant using pinch analysis. Appl. Therm. Eng. 2017, 117, 145-154.

41. Kong, L.; Wu, Y.; Maravelias, C. T. Simultaneous Utility and Heat Exchanger Area Targeting for Integrated Process Synthesis and Heat Integration. Ind. Eng. Chem. Res. 2017, 56, 11847-11849.

42. Yoon, S. G.; Lee, J.; Park, S. Heat integration analysis for an industrial ethylbenzene plant using pinch analysis. Appl. Therm. Eng. 2007, 27(5), 886-893.

43. Li, B. H.; Chang, C. T. Retrofitting Heat Exchanger Networks Based on Simple Pinch Analysis. Ind. Eng. Chem. Res. 2010, 49(8), 3967-3971.

44. Ibrahim, D.; Jobson, M.; Gosalbez, G. G. Optimization-based Design of Crude Oil Distillation Units using Rigorous Simulation Models. Ind. Eng. Chem. Res. 2017, 56(23), 6728-6740.

45. Yang. Y.; Liu, J.; Shen, W. F.; Li, J.; Chien, I. L. High-efficiency utilization of $\mathrm{CO}_{2}$ in the methanol production by a novel parallel-series system combining steam and dry methane reforming, Energy. 2018, 158, 820-829. 


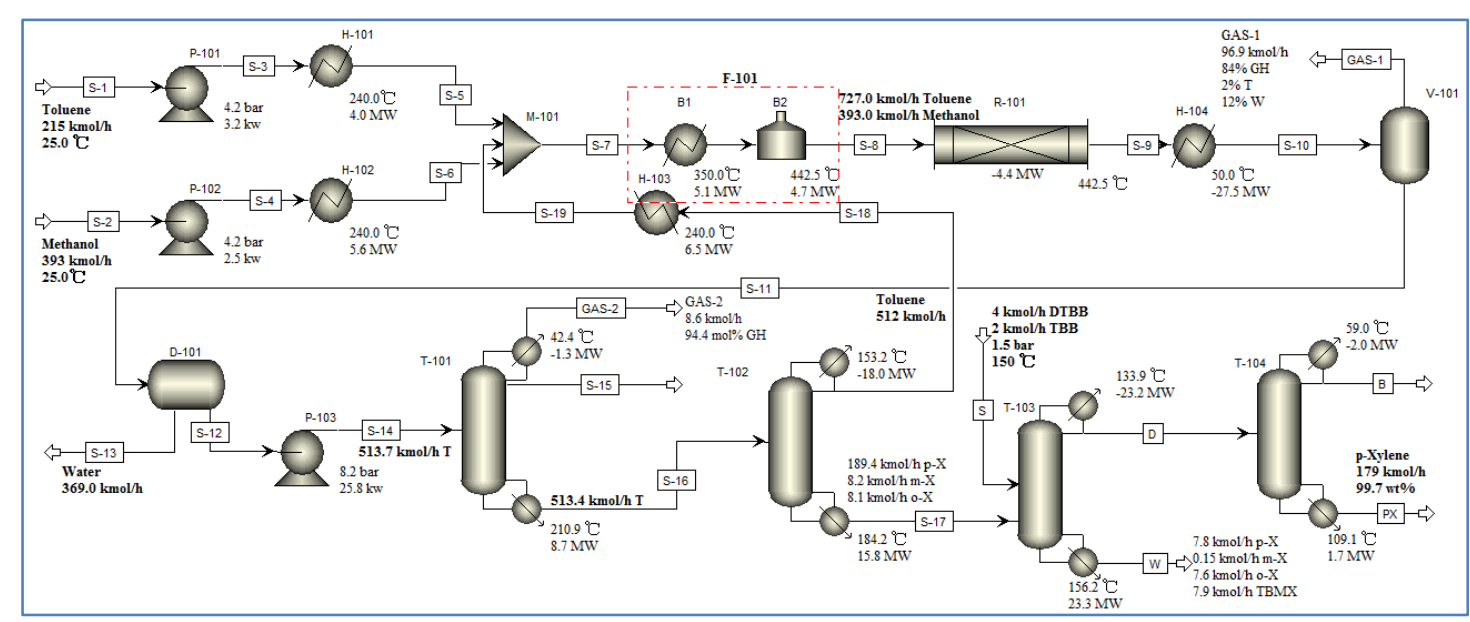

